\title{
Laser Ablation Mass Spectrometry of Inorganic Transition Metal Compounds. Additional Knowledge for the Understanding of Ion Formation
}

\author{
Frédéric Aubriet and Jean-François Muller \\ Laboratoire de Spectrométrie de Masse et de Chimie Laser, Université Paul Verlaine-Metz, Metz, France
}

Laser ablation of transition-metal oxides have been investigated to better understand the formation processes of inorganic cluster ions. The study of binary oxide mixtures and the relative distribution of the ions produced suggest three salient mechanisms that occur after laser/matter interaction, that function to produce the observed ensemble of ionic species. Molecular recombination reactions, unimolecular dissociation processes, emission of small neutrals, including molecular oxygen from transition-metal oxide samples, or from species expelled in gas phase appear to be a significant mechanism, especially under high laser irradiance conditions. These processes are used to propose a set of pathways to rationalize the envelope of ionic clusters formed under photon bombardment. (J Am Soc Mass Spectrom 2008, 19, 488-501) @ 2008 American Society for Mass Spectrometry

$\mathrm{T}$ The study of ion formation processes by mass spectrometry during inorganic compound laser ablation is not yet fully understood. However, several models have been proposed to describe and explain the laser ablation of inorganic compounds [1-7]. The interaction of a laser beam with a non-metallic solid induces different processes, leading to ejection of neutral and ionized species into the gas phase. Haglund proposed a qualitative description of these processes [7], which begins with the assumption that laser sputtering could be decomposed into four phases: (1) the absorption of laser energy by one or multiple-photon processes; (2) the conversion of the incident energy through radiative and non-radiative relaxation processes; (3) the ejection of species-atoms, molecules, neutrals, ions, excited species-from the irradiated surface; and (4) the formation and the expansion of a more or less dense plume of neutrals and ions. Two lasermatter interaction regimes have to be considered: the laser desorption (LD) and the laser ablation (LA). It is generally reported that LD results in emission of ions, atoms, and molecules without any substantial disturbance in the surrounding surface. LA implies a largescale disruption of surface and near-surface geometrical and electronic structure. These substantial qualitative differences allowed Haglung to identify desorption with a microscopic, and ablation with a mesoscopic view point. LD and LA have to be viewed as the extremes of a continuum, which ranges from the emis-

Address reprint requests to Dr. F. Aubriet, Laboratoire de Spectrométrie de Masse et de Chimie Laser, Université Paul Verlaine-Metz, 1 Boulevard Arago, F-57078 Metz Technopôle Cedex 03, France. E-mail: aubriet@univmetz.fr sion of isolated neutrals or ions in the case of LD to the massive removal of material resulting from the collective effects of multiple photons irradiating the same spatial locale in the case of LA. The phenomenology of LA is thought of in terms of formation of a plume of ejected species, which follows the laws of plasma and gas dynamics, and produces a large number of ionized species. Collisions of ions with neutrals occurring in the gas-phase plume after LA lead to ion-molecule condensation reactions. On the other hand, ions and neutrals possess a significant amount of energy, which can result in dissociation reactions. The length scale associated with laser ablation is on the order of $d \cong \tau_{\text {laser }} \times v_{s}$, where $\tau_{\text {laser }}$ is the duration of the laser pulse and $v_{s}$ is the speed of the sound. Indeed, the excitation, thermalization and lattice instability, which drive ablation process, occurred during the time scale of the full laser pulse duration. Consequently, the scale length for ablation is up to a few tens of microns and the amount of species expelled in gas phase is important [7].

Molecular dynamics (MD) simulation have been used to investigate and differentiate ablation and desorption processes. Prior MD studies have principally emphasized laser-organic matter interaction, motivated by interest in the field of matrix assixted laser desorption ionization (MALDI) experiments [8]. Recently, MD simulation of ultrafast laser ablation of silica has been reported [9]. During ultrafast laser irradiation (i.e., laser pulsewidths in the femtosecond time scale), the energy deposited at the surface of silica excites valence electrons in the material to the conduction band. The excited electrons absorb laser energy that is then transferred to the lattice, which induces an in- 
crease of the temperature and involves phase change (boiling and vaporization) that accompanies material decomposition. This process is commonly referred to as the "thermal ablation" component of the laser-matter interaction [9]. The liberation of free electrons may also have a significant influence on the ablation, leaving behind positively charged moieties subject to Coulombic repulsive forces, and contributing to ejection of the ablated material. Such electrostatic events are referred to as "nonthermal" ablation. Two MD simulations have been conducted by Cheng et al. at a laser energy higher than the reported laser ablation threshold for fused silica $\left(\sim 4.5 \mathrm{~J} / \mathrm{cm}^{2}\right)$. The first one neglected Coulombic repulsive forces associated with free electrons whereas the second one took them into account. In the first MD simulation, no material was ejected into the gas phase, which is in disagreement with experiments. In contrast, the calculations including electron effects demonstrated the separation of material and the ejection of species in the gas phase [9]. These calculations are in accordance with those reported by Knochenmuss and Zhigilei on the importance of electrons in laser-matter interaction of organic compounds [8]. Both the desorption and ablation regimes lead to the emission of free electrons in the gas phase from the top of the laser irradiated material, inducing a significant surface charge. The first ionic species emitted in the gas phase-mainly positive ions-are ejected by Coulomb repulsion. Later ions are entrained in the gas of neutral species that are in rough local equilibrium with surface (desorption) or cluster (ablation). Calculations also clearly indicated that ablation involves the disintegration of a relatively thick surface region and ejection of individual molecules as well as large clusters, producing a plume is dense enough to enable collisions. Collisions were also observed for MD simulations of desorption phenomenon $\sim 500$ ps after the laser-matter interaction, when the gas phase became dense enough [8].

The descriptions of Haglung [7], Knochenmuss and Zhigilei [8] are consistent with the two mechanisms reported to explain cluster ion formation, namely recombination and unimolecular dissociation. The factors that govern each of the processes are different. The intact ejection of a lattice fragment occurs if the energy involved is low enough to avoid complete atomization, but still sufficient to preferentially break some of the weakest bonds in the crystal. In the recombination model, particles properly correlated in time, space, and velocity associate in the gas phase to give the most stable species. It is also reported that both ion formation pathways may occur simultaneously; for example in a LA-MS study of $\mathrm{Co}\left(\mathrm{NO}_{3}\right)_{2} \quad 6 \mathrm{H}_{2} \mathrm{O}$ [10], both $\mathrm{Co}_{\mathrm{n}} \mathrm{O}_{\mathrm{m}}{ }^{+}$ recombination ions and $\left\{\mathrm{Co}\left[\mathrm{Co}\left(\mathrm{NO}_{3}\right)_{2}\right]_{\mathrm{n}} \cdot\left(\mathrm{H}_{2} \mathrm{O}\right)_{\mathrm{m}}\right\}^{+}$ions were observed. The importance of recombinaison has been further substantiated in other LA-MS experiments [11-18]. Finally, dissociative processes may also take place as a result of excess of internal energy from the desorption event, or collision with neutrals [19]. These processes have been proposed to explain the formation of highly oxygen deficient [20] or highly oxidized [21] species after laser ablation.

The comparison of LA-MS and s-SIMS measurements in the study of transition-metal oxides [22] allowed us to highlight some periodic trends and to demonstrate the relation between the distribution of metal valence sites in $\mathrm{M}_{\mathrm{x}} \mathrm{O}_{\mathrm{y}}^{+/-}$cluster ion and the electronic configuration of the metal. Our purpose in this paper is to propose general principles governing cluster ion formation by laser ablation. Consequently, we have evaluated the influence of the laser wavelength, sample preparation, and energy deposited at the sample surface (i.e., laser fluence or irradiance) on the LA mass spectra of metal oxides, salts, and their mixtures. More particularly, this paper is focused on the LA mass spectra of specific systems: hexavalent chromium oxide; bi-, tri-, tetra-, and pentavalent vanadium oxides; cupric oxide; trivalent yttrium oxide and ternary ironchromium-oxygen systems. These results will be succintly compared with those of other transition-metal oxides, enabling us to generalize the trends observed in the investigation of model systems.

\section{Experimental}

\section{Instrumentation}

Analyses are performed with an internal ion source Fourier transform ion cyclotron laser microprobe mass spectrometer (FTICR-LMMS), and a laser ablation time of flight secondary ion mass spectrometer (LATOFMS). FTICR-LMMS has been described in details elsewhere [22] as well as the instrumental parameters that were used.

In laser ablation Fourier transform ion cyclotron mass spectrometry (LA-FTICRMS) the irradiance is modified by focusing-defocusing an external telescope which allows modification of the laser spot size from a few microns to a few hundred microns. This enables the irradiance deposited at the surface to be varied from $5 \times 10^{6}$ to $4 \times 10^{10} \mathrm{~W} / \mathrm{cm}^{2}$. The laser energy is measured before entry into the mass spectrometer. The beam is optically attenuated, which is arithmetically accounted for by an attenuation factor relative to laser energy absorption that is applied to obtain the irradiance. The wavelength used is typically $355 \mathrm{~nm}$ (time duration $\tau=4.3 \mathrm{~ns})$, although $193(\tau=23 \mathrm{~ns})$ and 266 $(\tau=4.3 \mathrm{~ns}) \mathrm{nm}$ were also employed. Ion intensity in LA-FTICRMS experiments are generally given in relative intensity. Ions are produced by laser ablation in the first millisecond after the beginning of the FTICRMS sequence. After $5 \mathrm{~ms}$, ions are excited by the application of a $3 \mathrm{~ms}$ time sweep rate excitation, followed by recording the transied after an additional delay of $1 \mathrm{~ms}$. The transient duration is typically in the 8 to $32 \mathrm{~ms}$ range of time. The time between ion formation and the detection was kept as small as possible to favor detection of the ions produced directly by laser ablation, and not the species resulting from subsequent ion-molecule 
reactions with the residual neutrals present in the FTICRMS cell.

Additional LA-MS experiments were performed with a Bruker Reflex IV Maldi-TOF instrument (BrukerFranzen Analytik GmbH, Bremen, Germany) equipped with a delayed extraction. Ionization is achieved using a nitrogen laser $(\lambda=337 \mathrm{~nm}$, pulse duration: $3 \mathrm{~ns}$, output energy: $400 \mu \mathrm{J}$, repetition rate $5 \mathrm{~Hz}$ ). The laser spot size diameter is $\sim 30 \mu \mathrm{m}$. The laser fluence may be varied by means of an attenuator from 22 to 540 $\mathrm{mJ} / \mathrm{cm}^{2}$, producing irradiance values varying between $7.3 \times 10^{6}$ and $1.8 \times 10^{8} \mathrm{~W} / \mathrm{cm}^{2}$. The mass spectrometer was operated in the reflectron mode at a total acceleration voltage of $20 \mathrm{kV}$ and a reflecting voltage of $23 \mathrm{kV}$. Mass spectra are the sum of one hundred laser shots each targeting a fresh area of the sample surface. This was done to avoid variation of the mass spectrum resulting from laser matter interaction that could produce a significant alteration of the composition as well as the physical and chemical properties. The ion assignment is attained after external calibration performed with polyethylene glycol 600 and/or $1500 \mathrm{Na}^{+}$and $\mathrm{K}^{+}$ cationized ions. Postsource decay (PSD) experiments have been conducted with this instrument to evaluate the fragmentation of excited species in the free field region [23].

\section{Normalization}

To evaluate the influence of laser irradiance on the distribution of $\mathrm{M}_{\mathrm{x}} \mathrm{O}_{\mathrm{y}}{ }^{-}$ions $(\mathrm{M}=$ metal atom), two normalization processes are used. The first investigates the dependence of large cluster ion yield with laser irradiance. A normalized ion intensity $\left(\mathrm{Y}_{\mathrm{M}_{\mathrm{x}} \mathrm{O}_{1}^{-}}^{\mathrm{N}}\right)$ is generated for each envelope of $\mathrm{M}_{x} \mathrm{O}_{j}^{-}$ions for which the number of metal atoms (x) is fixed, but the number of oxygen atoms ( $\mathrm{j}$ ) is variable. This normalized ion intensity $\mathrm{Y}_{\mathrm{M}_{\mathrm{x}} \mathrm{O}_{1}^{-}}^{\mathrm{N}}$ is obtained by dividing, the sum of the $\mathrm{Y}_{\mathrm{M}_{\mathrm{x}} \mathrm{O}_{1}^{-}}^{\mathrm{A}}$ absolute ion intensity for a given series by the sum of absolute intensity of all of the $\mathrm{M}_{\mathrm{i}} \mathrm{O}_{\mathrm{j}}^{-}$detected species:

$$
\mathrm{Y}_{\mathrm{M}_{x} \mathrm{O}_{j}}^{\mathrm{N}}=\frac{\sum_{\mathrm{j}} \mathrm{Y}_{\mathrm{M}_{\mathrm{x}} \mathrm{O}_{\mathrm{j}}^{-}}^{\mathrm{A}}}{\sum_{\mathrm{i}} \sum_{\mathrm{j}} \mathrm{Y}_{\mathrm{M}_{\mathrm{i}} \mathrm{O}_{\mathrm{j}}^{-}}^{\mathrm{A}}}
$$

The second normalization process allows us to evaluate the influence of instrumental parameter on the extent to which the given $\mathrm{M}_{x} \mathrm{O}_{j}^{-}$ion envelopes are oxidized. The $\mathrm{Y}_{\mathrm{M}_{\mathrm{x}} \mathrm{O}_{\mathrm{j}}}^{\mathrm{A}}$ absolute intensity for each $\mathrm{M}_{\mathrm{x}} \mathrm{O}_{\mathrm{j}}^{-}$ ion is normalized to $\sum_{j} \mathrm{Y}_{\mathrm{M}_{\mathrm{x}} \mathrm{O}_{\mathrm{j}}^{\mathrm{A}}}^{\text {: }}$

$$
\mathrm{Y}_{\mathrm{M}_{\mathrm{x}} \mathrm{O}_{j}^{-}}^{\mathrm{R}}=\frac{\mathrm{Y}_{\mathrm{M}_{\mathrm{x}} \mathrm{O}_{\mathrm{j}}}^{\mathrm{A}}}{\sum_{\mathrm{j}} \mathrm{Y}_{\mathrm{M}_{\mathrm{x}} \mathrm{O}_{\mathrm{j}}}^{\mathrm{A}}}
$$

\section{Target Compounds and Sample Preparation}

The majority of first row transition-metal oxides were examined together with some alkaline chromates. All products (analytical grade from 97 to $99.9 \%$ ) were purchased from common suppliers (Aldrich, Fluka, Hereaus, Merck, Prolabo and Sigma). Iron chromite was synthesized according to the methodology developed by Manoharan [24] and the $\mathrm{FeO}-\mathrm{Cr}_{2} \mathrm{O}_{3}$ stoichiometric mixture was prepared by mechanic grinding in an agate mortar.

The oxide powders were formed into pellets using a pellet press, applying a pressure of $3 \mathrm{t} / \mathrm{cm}^{2}$ (tons per centimeter square) for $15 \mathrm{~min}$. Alternatively, some of the water-soluble compounds were prepared for analysis by applying a $5 \mathrm{~g} / \mathrm{L}$ solution to a stainless steel holder and evaporating, or were spin-coated onto silicon wafer or on polycrystalline gold substrate.

\section{Results and Discussion}

\section{Influence of Sample Preparation}

The relative distribution of cluster ions produced by LA is influenced by bonding in the sample targets. This was illustrated by comparing two ternary iron-chromiumoxygen systems that had the same atomic composition but different chemistry. $\mathrm{FeCr}_{2} \mathrm{O}_{4}$ was compared with a mechanically ground $\mathrm{FeO}-\mathrm{Cr}_{2} \mathrm{O}_{3}$ sample mixed such that the atomic ratios for $\mathrm{Fe} / \mathrm{Cr} / \mathrm{O}$ were $1 / 2 / 4$, respectively, to compare the stoichiometric mixture with the discrete compound. In addition, the effect of sample preparation was evaluted by comparing LA of pelletized solids with spectra acquired from samples that had been deposited as liquids and allowed to dry. Solution deposition was evaluated only for potassium chromate and chromium trioxide, due to insolubility of the majority of transition-metal oxides.

Study of $\mathrm{FeCr}_{2} \mathrm{O}_{4}$ and $\mathrm{FeO}-\mathrm{Cr}_{2} \mathrm{O}_{3}$ Stoichiometric Mixture. In the $100-160 \mathrm{~m} / \mathrm{z}$ range, numerous positive ions were observed at the $355 \mathrm{~nm}$ wavelength from both $\mathrm{FeCr}_{2} \mathrm{O}_{4}$ and the $\mathrm{FeO}-\mathrm{Cr}_{2} \mathrm{O}_{3}$ stoichiometric mixture (Figure 1). $\mathrm{Cr}_{2} \mathrm{O}_{\mathrm{y}}{ }^{+}$and $\mathrm{Fe}_{2} \mathrm{O}_{\mathrm{y}}{ }^{+}$species were detected in all analyses, as were mixed $\mathrm{Fe}-\mathrm{Cr}-\mathrm{O}$ ions. At even higher $\mathrm{m} / \mathrm{z}$ values, ions containing three or four metal atoms were observed, notably $\mathrm{Cr}_{3} \mathrm{O}_{3}{ }^{+}, \mathrm{Cr}_{2} \mathrm{FeO}_{3}{ }^{+}$, $\mathrm{CrFe}_{2} \mathrm{O}_{3}{ }^{+}, \mathrm{Cr}_{3} \mathrm{O}_{4}{ }^{+}, \mathrm{Cr}_{2} \mathrm{FeO}_{4}{ }^{+}, \mathrm{CrFe}_{2} \mathrm{O}_{4}{ }^{+}$, and $\mathrm{Cr}_{3} \mathrm{FeO}_{5}{ }^{+}$. In the negative detection mode mixed metal clusters were recorded, corresponding to $\mathrm{CrFeO}_{3}{ }^{-}, \mathrm{CrFeO}_{4}{ }^{-}$, $\mathrm{CrFeO}_{5}^{-}, \quad \mathrm{Cr}_{2} \mathrm{FeO}_{5}{ }^{-}, \quad \mathrm{Cr}_{2} \mathrm{FeO}_{6}{ }^{-}, \mathrm{Cr}_{2} \mathrm{FeO}_{7}{ }^{-}$, and $\mathrm{Cr}_{3} \mathrm{FeO}_{8}{ }^{-}$. Similar behavior was also observed in the examination of other ternary systems [17, 25].

Influence of the Sample Preparation. In LA-MS at the 355 nm wavelength, mass spectra obtained for $\mathrm{K}_{2} \mathrm{CrO}_{4}$ and $\mathrm{CrO}_{3}$ were very similar, regardless of whether sample preparation involved deposition of liquids or direct interrogation of pressed solids. Only slight differences 


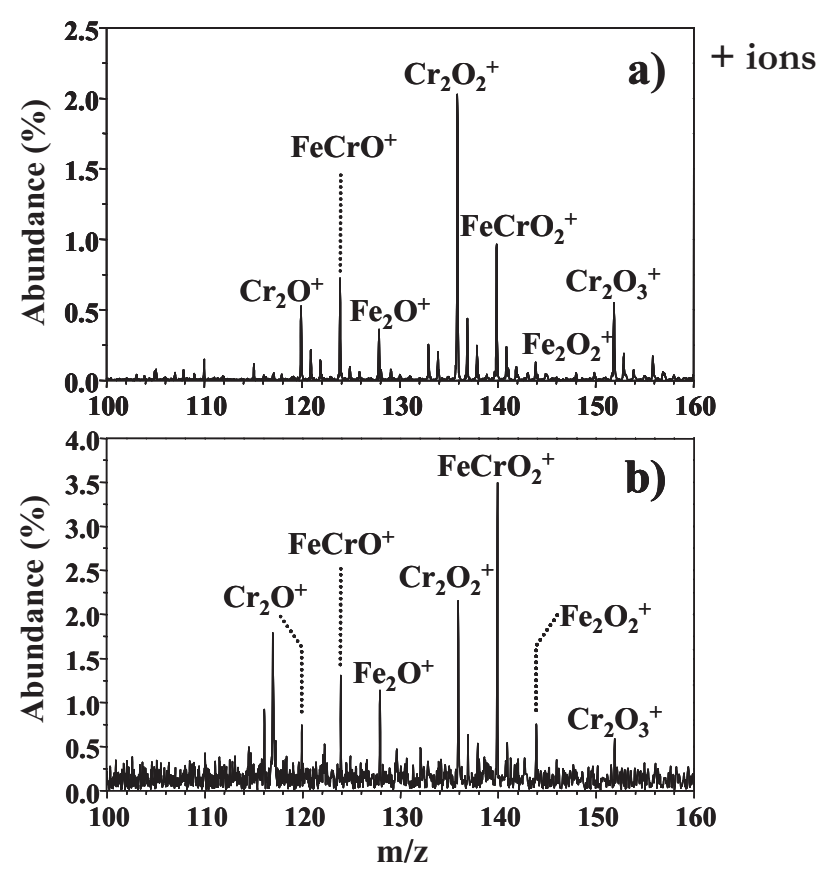

Figure 1. LA-FTICRMS positive mass spectra of (a) $\mathrm{FeCr}_{2} \mathrm{O}_{4}$ (b) $\mathrm{FeO}-\mathrm{Cr}_{2} \mathrm{O}_{3}$ stoichiometric mixture. LA-FTICRMS analyses were carried out with power densities of $6.3 \times 10^{7} \mathrm{~W} / \mathrm{cm}^{2}$ at the $355 \mathrm{~nm}$ wavelength.

in the relative distribution of $\mathrm{Cr}_{\mathrm{x}} \mathrm{O}_{\mathrm{y}}^{+/-}$ions were observed. However, ions containing $\mathrm{PO}_{2-3}{ }^{-}$ions appeared in the sample prepared by liquid deposition. The phosphate contamination may be derived from trace impurities in the water used or incorpated during the evaporation of water by deposition of atmospheric phosphate containing particles.

\section{Laser Wavelength Influence}

We previously reported mass spectra of chromium, molybdenum and tungsten trioxide at different wavelengths $(193,266$, and $355 \mathrm{~nm})$ [21, 26, 27]. In positive detection mode a dramatic decrease in the intensities of large cluster ions was observed with decreasing the wavelength. In negative detection mode the relative distribution of anions was less affected by the modification of the laser wavelength. For example, smaller amounts of the $\mathrm{Cr}_{\mathrm{x}} \mathrm{O}_{\mathrm{y}}{ }^{-}$cluster ions were detected at low laser wavelength, holding the irradiance constant at
$3 \times 10^{7} \mathrm{~W} \cdot \mathrm{cm}^{-2}$ (Table 1). This is indicated by a summation of the intensities of all ions emitted (expressed as total ion current or TIC), which decreases with decreasing wavelength, and indicates that smaller amounts of cluster ions were generally produced at lower wavelength. This behavior was also observed when the LA spectra of alkaline chromates were compared at 193 and $355 \mathrm{~nm}$ [19]. A greater energy per photon (6.42 and $3.49 \mathrm{eV}$ at 193 and $355 \mathrm{~nm}$, respectively) and a greater pulse duration are consistent with this behavior. The photodissociation of large species in the gas phase was more efficient when the energy per photon was greater, i.e., fewer photons were required at $193 \mathrm{~nm}$ to reach the dissociation threshold. Therefore, it may be assumed that more extensive fragmentation processes occurred at low laser ablation wavelength for inorganic compounds. Moreover, longer pulsewidth also favors more extensive dissociation processes.

\section{Variations of Chromium Trioxide and Vanadium Oxide Anion Distributions in LA-FTICRMS with the Energy Deposited at the Sample Surface at $355 \mathrm{~nm}$}

All of the transition-metal oxides investigated produced large amounts of cluster ions by laser ablation in both the positive and negative ion detection mode. $\mathrm{CrO}_{3}$ was used as the principal vehicle to investigate the influence of the energy deposited at the sample surface with the formation of cluster ions, although vanadium oxides were also examined for this purpose. Similar trends were observed for cluster ions of either polarity, and so we only present the behavior of negative cluster ions in this paper.

Variation of Chromium Trioxide Anion Distributions as a Function of Laser Irradiance at $355 \mathrm{~nm}$. The yield of the $\mathrm{Cr}_{x} \mathrm{O}_{j}^{-}$clusters $\left(\mathrm{Y}_{\mathrm{Cr}_{\mathrm{x}} \mathrm{O}^{-}}^{\mathrm{N}}\right)$ varies inversely with irradiance (Figure 2), which is consitent with previously reported research [15]. Only small cluster ions were produced under high irradiance conditions $\left(5 \times 10^{8}\right.$ to $4 \times 10^{10}$ $\mathrm{W} / \mathrm{cm}^{2}$ ) while at lower irradiances larger species were produced. In contrast, cluster ions containing up to 20 atoms $\left(\mathrm{Cr}_{5} \mathrm{O}_{15}{ }^{-}\right)$were observed when the irradiance was lowered to $10^{7} \mathrm{~W} / \mathrm{cm}^{2}$. This behavior has been

Table 1. Total ion current (TIC) and relative abundance of negative ions produced by laser irradiation of chromium trioxide at the $193,248,266$, and $355 \mathrm{~nm}$ wavelengths at an irradiance of $3 \times 10^{7} \mathrm{~W} . \mathrm{cm}^{-2 *}$

\begin{tabular}{|c|c|c|c|c|c|c|c|c|c|c|c|c|c|c|}
\hline \multirow[b]{2}{*}{ Wavelength } & \multirow[b]{2}{*}{$\tau$} & \multirow[b]{2}{*}{$\begin{array}{c}\text { Energy per } \\
\text { photon }\end{array}$} & \multirow[b]{2}{*}{ TIC } & \multicolumn{2}{|c|}{$\mathrm{CrO}_{\mathrm{y}}{ }^{-}$} & \multicolumn{3}{|c|}{$\mathrm{Cr}_{2} \mathrm{O}_{\mathrm{y}}{ }^{-}$} & \multicolumn{3}{|c|}{$\mathrm{Cr}_{3} \mathrm{O}_{\mathrm{y}}^{-}$} & \multicolumn{3}{|c|}{$\mathrm{Cr}_{4} \mathrm{O}_{\mathrm{y}}^{-}$} \\
\hline & & & & 2 & 3 & 4 & 5 & 6 & 7 & 8 & 9 & 10 & 11 & 12 \\
\hline $193 \mathrm{~nm}$ & $23 \mathrm{~ns}$ & $6.42 \mathrm{eV}$ & 306.4 & - & 7 & - & 4 & 100 & 1 & 5 & 45 & 3 & 4 & 10 \\
\hline $248 \mathrm{~nm}$ & $34 \mathrm{~ns}$ & $5.00 \mathrm{eV}$ & 400.3 & 7 & 100 & 2 & 11 & 35 & 1 & 1 & 3 & - & - & - \\
\hline $266 \mathrm{~nm}$ & $4.3 \mathrm{~ns}$ & $4.66 \mathrm{eV}$ & 454.2 & - & 26 & - & 10 & 100 & 1 & 3 & 17 & 1 & 1 & 3 \\
\hline $355 \mathrm{~nm}$ & $4.3 \mathrm{~ns}$ & $3.49 \mathrm{eV}$ & 560.7 & - & 12 & - & 3 & 100 & 2 & 6 & 26 & 5 & 4 & 6 \\
\hline
\end{tabular}

*Measurements have been conducted by LA-FTICRMS; $\tau$ refers to laser pulse width. 


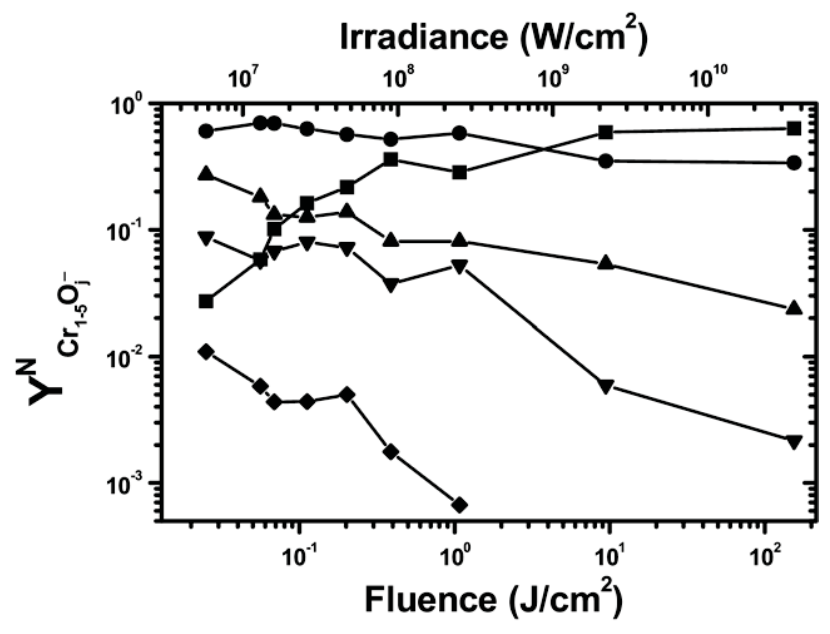

Figure 2. Evolution of the $\mathrm{Y}_{\mathrm{Cr}_{\mathrm{x}} \mathrm{O}_{1}^{-}}^{\mathrm{N}}$ in the study of chromium trioxide as a function of laser irradiance for $\mathrm{CrO}_{j}^{-}(\mathbf{\square}) ; \mathrm{Cr}_{2} \mathrm{O}_{j}^{-}(\mathbf{\bullet})$; $\mathrm{Cr}_{3} \mathrm{O}_{\mathrm{j}}^{-}(\boldsymbol{\Delta}) ; \mathrm{Cr}_{4} \mathrm{O}_{\mathrm{j}}^{-}(\boldsymbol{\nabla})$, and $\mathrm{Cr}_{5} \mathrm{O}_{\mathrm{j}}^{-}(\bullet)$ ions at the $355 \mathrm{~nm}$ wavelength.

previously observed in the study of alkaline chromate compounds by LA-MS [19].

The yield for the $\mathrm{Cr}_{3} \mathrm{O}_{\mathrm{j}}^{-}$oxyanions $\left(\mathrm{Y}_{\mathrm{Cr}_{3} \mathrm{O}_{1}^{-}}^{\mathrm{R}}\right)$ presents an anomaly, in that at very high irradiance $\left(>10^{10}\right.$ $\mathrm{W} / \mathrm{cm}^{2}$ ), the yield of $\mathrm{Cr}_{3} \mathrm{O}_{9}{ }^{-}$was significantly greater than the yield of the $\mathrm{Cr}_{3} \mathrm{O}_{7,8}{ }^{-}$anions (Figure 3). This has been attributed to the sublimation of $\left(\mathrm{CrO}_{3}\right)_{1-5}$ neutral species followed by electron capture [21]. The most highly oxygenated species are somewhat attenuated over the range of laser irradiance values $10^{7}$ to $2 \times 10^{8}$ $\mathrm{W} / \mathrm{cm}^{2}$ and over this range, the relative distribution of $\mathrm{Cr}_{3} \mathrm{O}_{7-9}{ }^{-}$ion intensity remains relatively constant. At the lowest irradiance values (down to about $1 \times 10^{7}$ $\mathrm{W} / \mathrm{cm}^{2}$ ), the relative abundance of $\mathrm{Cr}_{3} \mathrm{O}_{9}{ }^{-}$increases again. Similar behavior is observed with other $\mathrm{Cr}_{\mathrm{x}} \mathrm{O}_{\mathrm{y}}{ }^{-}$ ion series $(x=1$ to 5$)$.

Variation of Vanadium Oxyanion Distributions as a Function Laser Irradiance at $355 \mathrm{~nm}$. The distribution of vanadium oxyanions followed trends that were similar to those observed for the $\mathrm{Cr}$ oxyanion systems. Increased laser irradiance leads to decreased intensities of the large cluster ion series and of the more highly oxygenated ions. The spectra of the different vanadium oxides contain differences in oxyanion relative abundances that may be used for identification of the solid materials based on their mass spectra. As previously reported [22], the different vanadium oxides emit the same species by laser ablation. The convention adopted for writing the compositions of the vanadium oxyanions is to denote them as combinations of small anions and small neutral molecules, i.e., denoting $\mathrm{V}_{3} \mathrm{O}_{7}{ }^{-}$as $\left(\mathrm{VO}_{2}\right)_{3} \mathrm{O}^{-}$. This notation does not connote explicit structural chemistry, in this case two discrete oxide molecules ionically bound by an oxide anion, as it is well known that charge delocalized ([22] and references therein), and that atoms are partly covalently bound by transition-metal-oxygen bounds. We adopted this approach for writing the ion formulae to maintain consistency with prior publications and because it facilitates discussion of ion formation mechanisms.

Plots of $\left(\mathrm{VO}_{2}\right)_{3} \mathrm{O}^{-}$and $\left(\mathrm{V}_{2} \mathrm{O}_{5}\right)\left(\mathrm{VO}_{2}\right) \mathrm{O}^{-}$as a function of laser irradiance for bi-, tri-, tetra-, and pentavalent vanadium oxides show that the extent of oxidation is inversely proportional to irradiance, and that oxidation increases with the oxidation state of the vanadium oxide target (Figure 4). In the spectra acquire for $\mathrm{VO}$, $\mathrm{Y}_{\mathrm{V}_{3} \mathrm{O}_{7}^{-}}^{\mathrm{R}}$ was greater than $\mathrm{Y}_{\mathrm{V}_{3} \mathrm{O}_{8}^{-}}^{\mathrm{R}}$ at all irradiance values. This is generally true for the other vanadium oxides acquired at high irradiance values, however, as irradiance decreases to around $10^{7} \mathrm{~W} / \mathrm{cm}^{2}, \mathrm{Y}_{\mathrm{V}_{3} \mathrm{O}_{8}}^{\mathrm{R}}$ becomes greater than $\mathrm{Y}_{\mathrm{V}_{3} \mathrm{O}_{7}^{-}}^{\mathrm{R}}$. The tri-, tetra-, and pentavalent vanadium oxides do display different behaviors at low irradiance values. $\mathrm{Y}_{\mathrm{V}_{3} \mathrm{O}_{7}^{-}}^{\mathrm{R}}$ and $\mathrm{Y}_{\mathrm{V}_{3} \mathrm{O}_{8}^{-}}^{\mathrm{R}}$ were nearly equivalent for $\mathrm{V}_{2} \mathrm{O}_{3}$, whereas $\mathrm{Y}_{\mathrm{V}_{3} \mathrm{O}_{8}^{-}}^{\mathrm{R}}$ became significantly greater for $\mathrm{V}_{2} \mathrm{O}_{4}$ and $\mathrm{V}_{2} \mathrm{O}_{5}$. Thus, the evolution of $\mathrm{V}_{3} \mathrm{O}_{7}{ }^{-}$ and $\mathrm{V}_{3} \mathrm{O}_{8}{ }^{-}$ions with the irradiance is dependent on the vanadium chemical state, raising the possibility to differentiate these compounds by measuring the irradiance required to observe the $\mathrm{Y}_{\mathrm{V}_{3} \mathrm{O}_{8}^{-}}^{\mathrm{R}}-\mathrm{Y}_{\mathrm{V}_{3} \mathrm{O}_{7}^{-}}^{\mathrm{R}}$ inversion.

Laser Ablation-Laser Desorption Threshold for Chromium Trioxide and Vanadium Pentoxide. The variations observed in the mass spectra of $\mathrm{CrO}_{3}$ and vanadium oxides with laser power density may be used to evaluate the limit between laser ablation and laser desorption of these compounds at the $355 \mathrm{~nm}$. Large cluster ions and "stoichiometric" species were evidenced at low laser power, and are indicators of laser desorption. In contrast, the smaller species and more intense deoxygenated ions were observed at high laser irradiance and hence are indicative of laser ablation. The total number of desorbed or ablated ions produced (total ion current or TIC) was also found to be highly dependent

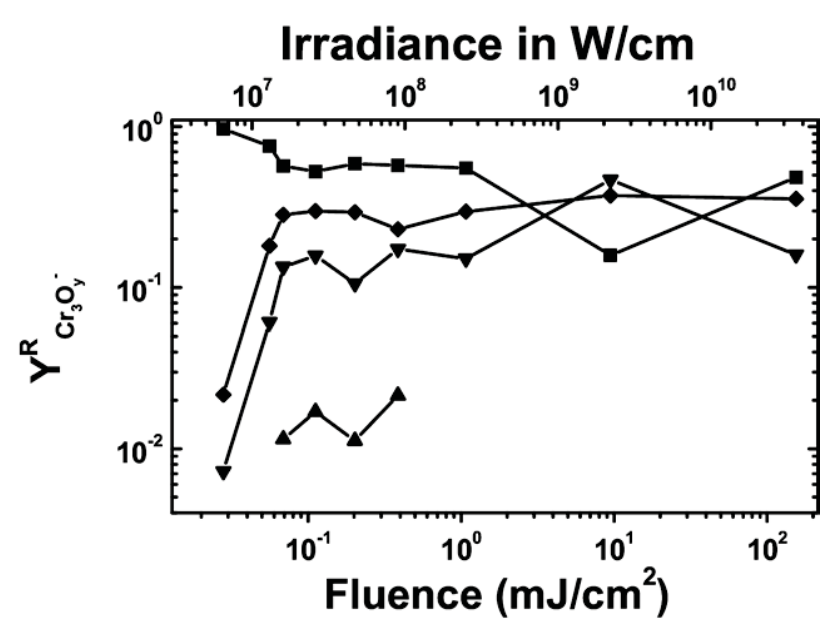

Figure 3. Evolution of the $\mathrm{Y}_{\mathrm{Cr}_{3} \mathrm{O}}^{\mathrm{R}}$ in the study of chromium trioxide as a function of laser irradiance for $\mathrm{Cr}_{3} \mathrm{O}_{6}{ }^{-}(\mathbf{\Lambda}) ; \mathrm{Cr}_{3} \mathrm{O}_{7}^{-}$ $(\boldsymbol{\nabla}) ; \mathrm{Cr}_{3} \mathrm{O}_{8}^{-}(\bullet)$ and $\mathrm{Cr}_{3} \mathrm{O}_{9}^{-}(\boldsymbol{\nabla})$ ions at the $355 \mathrm{~nm}$ wavelength. 

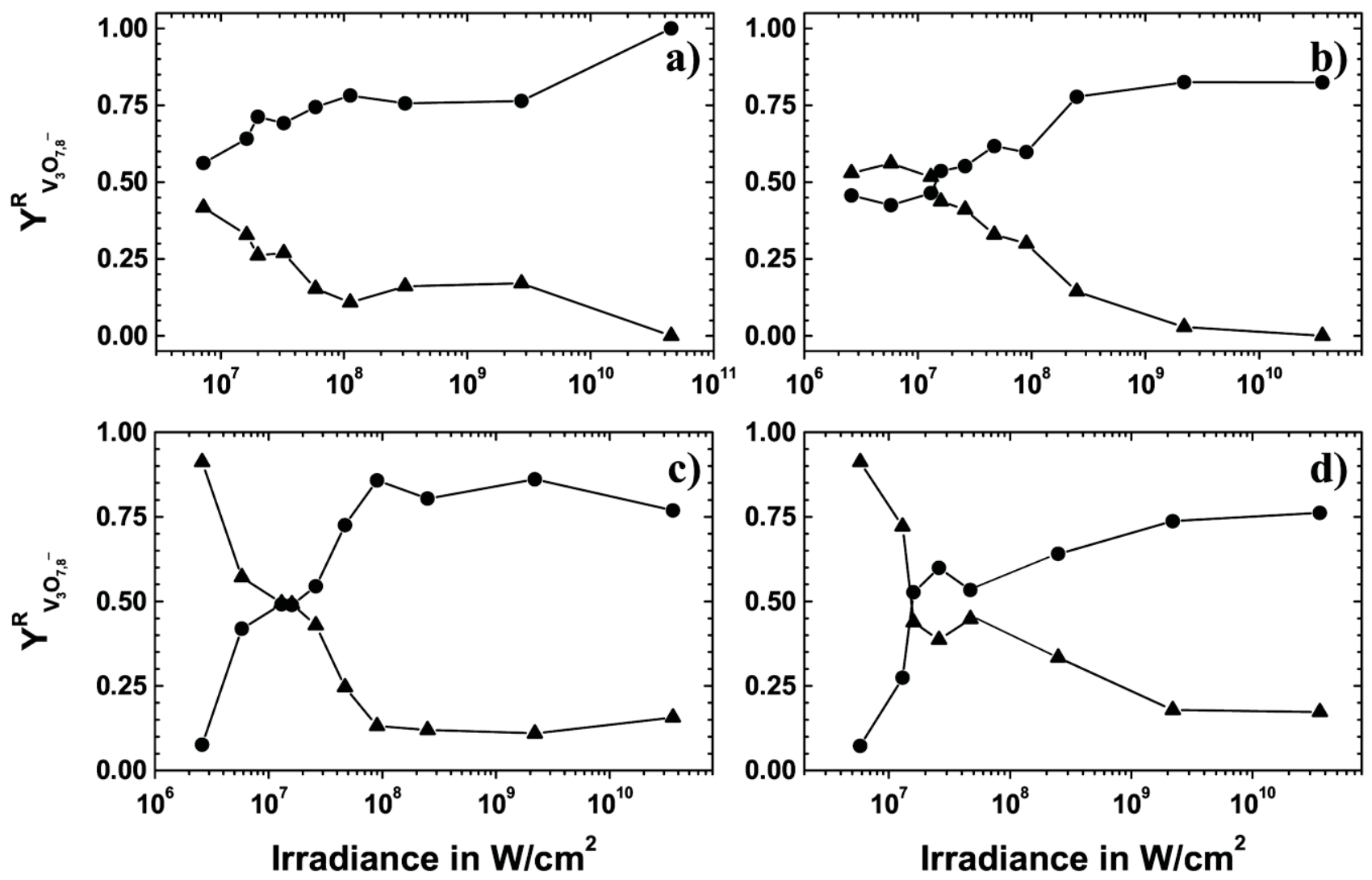

Figure 4. Relative distribution of $(\mathbf{O}) \mathrm{V}_{3} \mathrm{O}_{7}{ }^{-}$and $(\mathbf{\Delta}) \mathrm{V}_{3} \mathrm{O}_{8}{ }^{-}$ions in the study of (a) bi-, (b) tri-, (c) tetra-, and (d) pentavalent vanadium oxides.

of the laser energy, as shown in Figure 5 for chromium trioxide and vanadium pentoxide. Both compouds displayed common behavior at low laser power density: for irradiance values lower than the ablation/ionization threshold (estimated to $1.05 \times 10^{7}$ and $3.2 \times 10^{7} \mathrm{~W} / \mathrm{cm}^{2}$ for $\mathrm{CrO}_{3}$ and $\mathrm{V}_{2} \mathrm{O}_{5}$ respectively, see below) but greater than the desorption/ionization threshold, the TIC emission monotonically increased to a maximum value, above which it decreased, behavior that was consistent with previous studies of sodium chromate behavior under LA conditions [19]. This behavior may be interpreted as the transition between laser desorption and laser ablation. Molecular dynamics (MD) simulations [8] indicate that laser desorption ensures the emission of individual species with a restricted number of collisions occurring in the gas-phase plume. The collective effects induced by laser ablation lead to the ejection of large clusters, which may be viewed as particles. Emission of large clusters under conditions of many collisions tend to reduce total ion emission (TIC). Part of these collisions may induce the neutralisation of ions by recombination between positively and negatively charged species. Consequently, the irradiance corresponding to the maximum of the TIC may be considered as an appropiate value for the limit of ablation. It has also to be noted that the high collision rate in ablation regime induces dissociation of large ions and the elimination of oxygen atoms and molecules and $\mathrm{M}_{\mathrm{x}} \mathrm{O}_{\mathrm{y}}$ neutrals as well. Finally, chromium trioxide presents an additional process at high laser irradiance and leads to an increase in the TIC: the laser ablation induces the sublimation of the chromium trioxide and

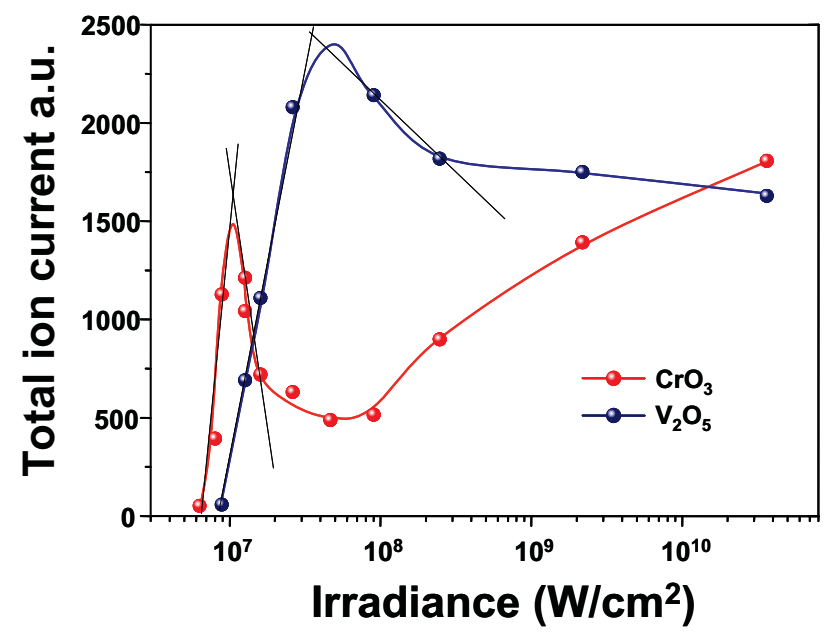

Figure 5. Total ion current of $\mathrm{M}_{\mathrm{x}} \mathrm{O}_{\mathrm{y}}{ }^{-}$cluster ions as a function of laser irradiance at the $355 \mathrm{~nm}$ wavelength for chromium trioxide and vanadium pentoxide. Lines correspond to the fitting of the data to determinate the ablation/ionization threshold. 
the formation of neutrals, which are ionized by thermoelectrons [21]. For $\mathrm{CrO}_{3}$, this limit may be compared with the laser irradiance that produces significant substoichiometric $\mathrm{Cr}_{3} \mathrm{O}_{6-8}{ }^{-}$anions (Figure 3), which is $\sim 1.6$ $\times 10^{7} \mathrm{~W} / \mathrm{cm}^{2}$. For vanadium oxides, the development of the relative abundance of $\mathrm{V}_{3} \mathrm{O}_{6,8}{ }^{-}$ions may be considered. It was found to be close to $10^{7} \mathrm{~W} / \mathrm{cm}^{-2}$ for $\mathrm{CrO}_{3}$ and between $2 \times 10^{7}$ and $3 \times 10^{7} \mathrm{~W} / \mathrm{cm}^{-2}$ pentavalent vanadium oxide. For $\mathrm{VO}, \mathrm{V}_{2} \mathrm{O}_{3}$, and $\mathrm{V}_{2} \mathrm{O}_{4}$, it was been found to be close to $8 \times 10^{7}, 4 \times 10^{8}$, and $10^{8}$ $\mathrm{W} / \mathrm{cm}^{-2}$, respectively.

\section{Principles for Better Prediction of Ion Formation by Laser-Matter Interaction}

In this section, we will try to rationalize the experimental evidence described in the previous sections with respect to previously published works to propose principles to better rationalize and predict cluster ion formation by photon irradiation. After considering the modification of sample surface under photon bombardment, the balance between direct emission and recombination will be discussed first, and then dissociation processes will be emphasized. The contrast between our model with published models will lead us to describe a global model of inorganic ion formation by laser irradiation in the last part of this section.

Modification of Surface Chemistry Under Photon Irradiation. Photon bombardment of the surface produces changes in the morphology and stoichiometry [7] that can be correlated with processes produce cluster ions.

Thermodynamic calculations were used to explain the significant loss of oxygen occurs during ablation of various transition-metal oxides [28, 29], that were consistent with the formation of sub-stoichiometric metal oxides reported by Sol and Tilley. They noted color modifications of the surface when stoichiometric metal oxides were irradiated at $308 \mathrm{~nm}$ with laser irradiance in the $3.2 \times 10^{5}-1.4 \times 10^{8} \mathrm{~W} / \mathrm{cm}^{2}$ range [30]. $\mathrm{CuO}$ irradiated at $355 \mathrm{~nm}$ (Figure 6) showed a dramatic decrease in the intensity of large cluster cations and oxy-cations (e.g., trend for the $\mathrm{Cu}_{3} \mathrm{O}^{+}$ion), and a concomitant increase in the intensity of bare metal ions, especially $\mathrm{Cu}_{2}{ }^{+}$. These observations indicated surface modification, specifically leading to oxygen impoverishment that facilitated formation of bare metal ions and nonstoichiometric laser ablation. The area that underwent multiple laser shots displayed modified coloration, specifically an orange-red color, indicative of metallic copper, which contrasted sharply with $\mathrm{CuO}$, which is black. Consequently, the evolution of the relative distribution of ions in the mass spectra reported in Figure 6 may be related to a reduction process of cupric oxide forming metallic copper, i.e., oxygen impoverishment.

Photon bombardment lead to significant reduction at the surface of the sample by non-stoichiometric laser

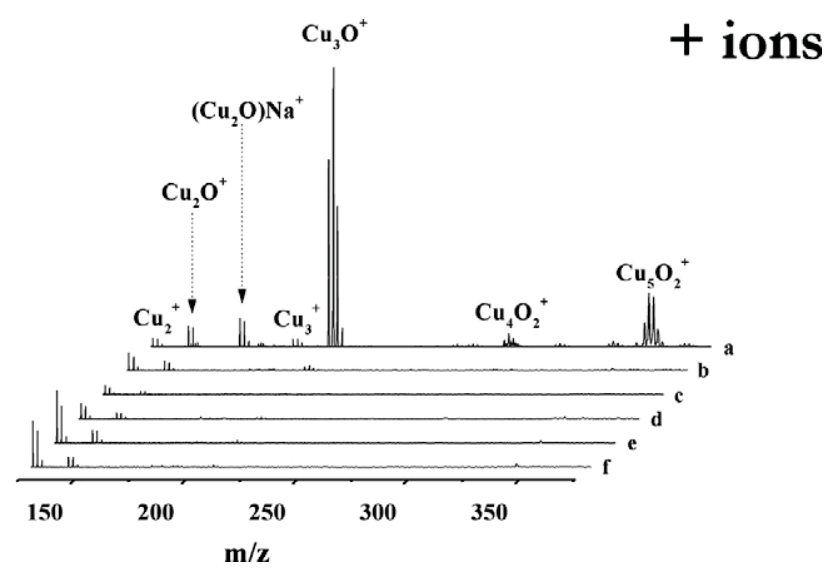

Figure 6. Evolution of FTICR laser ablation $\mathrm{CuO}$ positive mass spectrum with the number $\mathrm{N}$ of laser impacts on the same place prior analysis. $N=$ (a) 0, (b) 500, (c) 1000, (d) 1500, (e) 2500, and (f) 3500 , respectively. FTICR mass spectrum are acquired at $355 \mathrm{~nm}$ with an irradiance of $5 \times 10^{7} \mathrm{~W} / \mathrm{cm}^{2}$.

ablation. The amounts of oxygen species (atomic or molecular) in the gas cloud formed by the species ejected from the surface are consequently important and may play an important role during and after the formation of cluster ions. Finally, the release of oxygen atoms from the surface leads to the formation of crystal defects, which may ensure an easier ejection of small ions.

Direct Emission or Recombination. A comparison of the mass spectra of iron chromite with a stoichiometric FeO- $\mathrm{Cr}_{2} \mathrm{O}_{3}$ mixture by LA at $355 \mathrm{~nm}$ showed that recombination processes were important in gas phase during and/or after laser ablation. They were responsible of the $\mathrm{FeCrO}_{1,2}{ }^{+}$ion detection in the analysis of the stoichiometric $\mathrm{FeO}-\mathrm{Cr}_{2} \mathrm{O}_{3}$ mixtures, producing results that were consistent with those of previous studies [25].

In LA-MS experiments the large quantity of matter ablated enabled gas-phase recombination to occur. High kinetic energy and broad kinetic energy distribution (KED) in the 45 to $65 \mathrm{eV}$ range have been reported for the $\mathrm{KrF}$ laser ablation of metal and oxide semiconductor [6, 31]. KED values of $6.2 \mathrm{eV}$ have been reported for $\mathrm{Ta}^{+}$ion ablated from $\mathrm{Ta}_{2} \mathrm{O}_{5}$ with $532 \mathrm{~nm}$ irradiation at $0.7 \mathrm{~J} / \mathrm{cm}^{2}$ [32]. Moreover Park and Moon also demonstrated an increase of mean ion kinetic energies with the increase of laser fluence [33]. Consequently, ions ejected from the surface by photon bombardment and formed by recombination processes required buffer species to dissipate excess energy. The participation of a third body could help to stabilize these ions as has been observed in molecular beam machines [34, 35], laser cluster sources [36], and also in static SIMS. Indeed, Gianotto et al. observed higher secondary abundances using a quadrupole ion trap, where He bath gas likely functioned to stabilize emitted molecular species [37]. In LA-MS experiments, relatively volatile target components (e.g., nitrogen, oxygen, water, carbon oxides, 
nitrogen oxides, sulfur oxides) [38] can generate a localized vapor pressure of atoms and small molecules that would be able to function as a third body for thermalization or recombination reactions occurring in the ablation plume. The production of larger cluster ions from lanthanide oxalate [39] or chromium sulfate [26], compared with smaller clusters from lanthanide oxides and chromium oxides respectively, has been rationalized in similar terms. In these later cases, $\mathrm{CO}_{\mathrm{x}}$ or $\mathrm{SO}_{\mathrm{x}}$ neutrals were hypothesized to facilitate the formation of large $\mathrm{M}_{\mathrm{x}} \mathrm{O}_{\mathrm{y}}^{+/-}$cluster ions by providing collisional stabilization.

Recombination or direct ejection processes may also lead to the production of hot cluster ions due to an incomplete or inefficient cooling by third body collision. These excited species may undergo dissociation events to dissipate excess internal energy. Consequently, cluster ion distribution may reflect the superposition of both processes, i.e., recombination and dissociation, and can be described statistically using a Poisson distribution. It has been previously reported that cluster ion intensity in LA-MS experiments will conform to Poisson distribution [40], where $P_{n}$ (intensity of the $\left.\left(\mathrm{M}_{\mathrm{x}} \mathrm{O}_{\mathrm{y}}\right)_{\mathrm{n}} \mathrm{X}^{+/-}\right)$may be correlated according to

$$
\mathrm{P}_{\mathrm{n}}=\mathrm{P}_{0} \times \frac{(\mathrm{kt})^{\mathrm{n}}}{\mathrm{n} !} \times \exp (-\mathrm{kt})
$$

where $P_{0}$ is the intensity of the $\mathrm{X}^{+/-}$ion and $k t$ is a parameter that associates the reaction time $t$ to global rate constant $k$ of cluster growth and/or dissociation reactions, i.e., $k$ is a combination of the rate constants of formation and dissociation associated to a cluster ion, and $n$ is the number of $\mathrm{M}_{\mathrm{x}} \mathrm{O}_{\mathrm{y}}$ subunits. If aggregation processes are missing or of low efficiency or if significant dissociation processes occur small $k t$ values are expected. In contrast high values of $k t$ indicate significant recombination and aggregation processes and/or

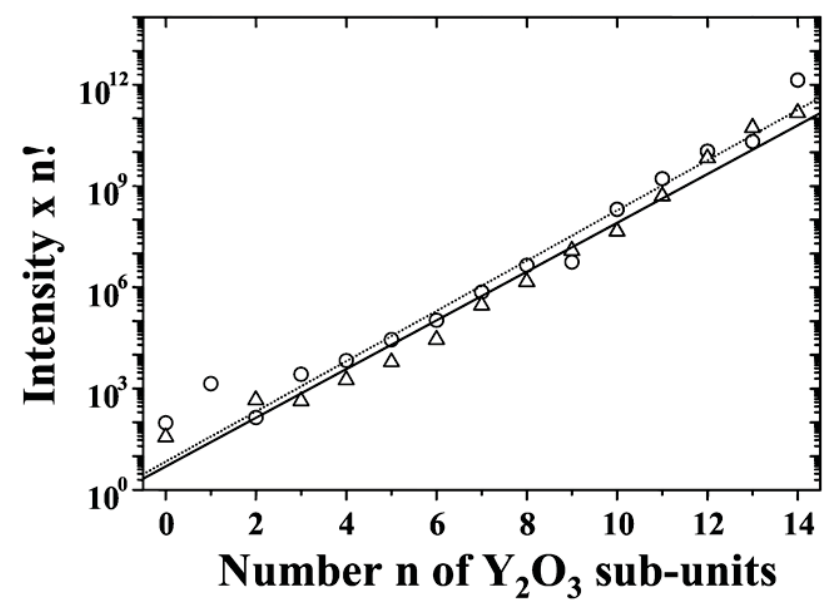

Figure 7. Poisson distribution deconvolution for $\left(\mathrm{Y}_{2} \mathrm{O}_{3}\right)_{n} \mathrm{YO}^{+}$ (open circle) and $\left(\mathrm{Y}_{2} \mathrm{O}_{3}\right)_{n} \mathrm{Y}_{2} \mathrm{O}_{2}{ }^{+}$(open triangle) positive ion series obtained in the study of yttrium oxide by LA-FTICRMS at the 355 $\mathrm{nm}$ wavelength. Data from reference 26.
Table 2. kt Poisson parameter obtained in the analysis of $\left(\mathrm{Y}_{2} \mathrm{O}_{3}\right)_{\mathrm{n}} \mathrm{YO}^{+}$and $\left(\mathrm{Y}_{2} \mathrm{O}_{3}\right)_{\mathrm{n}} \mathrm{Y}_{2} \mathrm{O}_{2}{ }^{+}$cluster ions by LA-FTICRMS at the $355 \mathrm{~nm}$ wavelength

\begin{tabular}{llc}
\hline & lon series & kt \\
\hline \hline LA-MS & $\left(\mathrm{Y}_{2} \mathrm{O}_{3}\right)_{\mathrm{n}} \mathrm{YO}^{+}$ & $2.39 \pm 0.13$ \\
& $\left(\mathrm{Y}_{2} \mathrm{O}_{3}\right)_{n} \mathrm{Y}_{2} \mathrm{O}_{2}{ }^{+}$ & $2.30 \pm 0.18$ \\
\hline
\end{tabular}

inefficient dissociation events. This model was used to rationalize $\left(\mathrm{Y}_{2} \mathrm{O}_{3}\right)_{\mathrm{n}} \mathrm{YO}^{+}$and $\left(\mathrm{Y}_{2} \mathrm{O}_{3}\right)_{\mathrm{n}}(\mathrm{YO}) \mathrm{YO}^{+}$cluster ions generated in $\mathrm{Y}_{2} \mathrm{O}_{3}$ laser ablation (Figure 7, Table 2). Yttrium oxide was used in this evaluation because (1) this oxide produces a significant yield of cluster ions and, (2) only one building block, i.e., $\mathrm{Y}_{2} \mathrm{O}_{3^{-}}$is involved in the structure of the observed cluster ions, in contrast to other compounds investigated [22]. This model produced high $k t$ values for spectra obtained in LA-MS experiments at $355 \mathrm{~nm}$ for all the examined cluster ion series, which indicates inefficient or slow dissociation during and/or after laser matter interaction and/or significant recombination and/or aggregation processes.

The occurrence of dissociative processes after cluster ion emission supports postsource decay (PSD) measurements performed on $\mathrm{Cr}_{4} \mathrm{O}_{10}{ }^{+}$species produced by chromium trioxide laser ablation at the $337 \mathrm{~nm}$ wavelength (Figure 8) using a time of flight mass spectrometer. The fragmentation of this ion in the free field region is driven by the need to release excess internal energy. Likely different dissociation channels were operating: loss of an oxygen atom or an $\mathrm{O}_{2}$ molecule, and loss of various chromium-oxygen $\mathrm{Cr}_{\mathrm{x}} \mathrm{O}_{\mathrm{y}}$ species such as $\mathrm{CrO}_{3}$. Moreover, it was clear that fragmentation processes were highly dependent on the laser fluence: higher values resulted in excess of internal energy and more efficient dissociation. To validate this hypothesis chromium trioxide was examined by TOF-MS at $337 \mathrm{~nm}$ ablation, with and without an additional excitation of species in the gas phase by a $266 \mathrm{~nm}$ laser. The $337 \mathrm{~nm}$

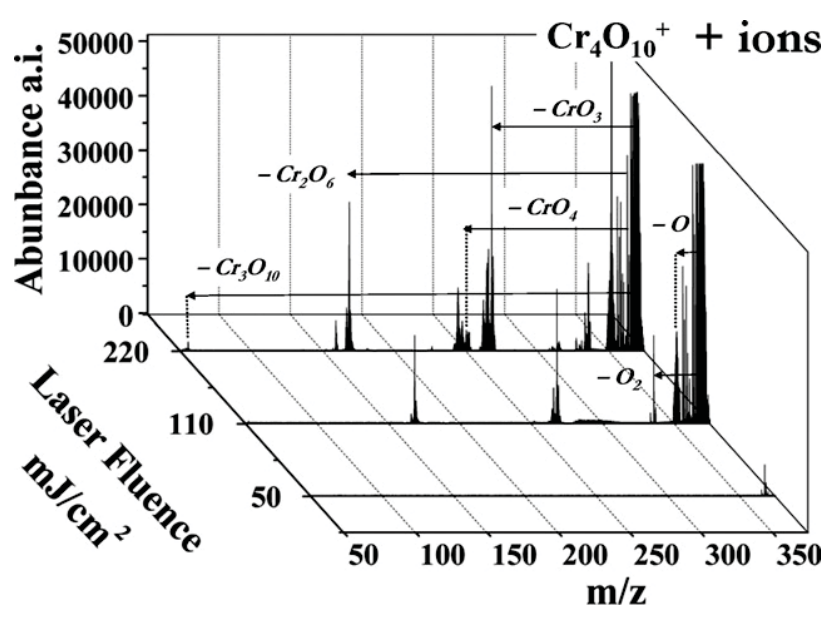

Figure 8. PSD mass spectra of $\mathrm{Cr}_{4} \mathrm{O}_{10}{ }^{+}$ion produced by laser ablation of chromium trioxide at $337 \mathrm{~nm}$ as a function of laser fluence. 
Table 3. Relative intensity of cluster anions observed in the study of chromium trioxide by LA-TOF-MS at $337 \mathrm{~nm}$ with or without additional gas-phase excitation at $266 \mathrm{~nm}$

\begin{tabular}{lccc}
\hline \multicolumn{1}{c}{ Ion } & $\mathrm{m} / z$ & $337 \mathrm{~nm}$ & $337+266 \mathrm{~nm}$ \\
\hline \hline $\mathrm{CrO}_{3}{ }^{-}$ & 100 & 1 & 23 \\
$\mathrm{HCrO}_{4}{ }^{-}$ & 117 & 1 & 2 \\
$\mathrm{Cr}_{2} \mathrm{O}_{5}^{-}$ & 184 & - & 3 \\
$\mathrm{Cr}_{2} \mathrm{O}_{6}{ }^{-}$ & 200 & 43 & 100 \\
$\mathrm{HCr}_{2} \mathrm{O}_{7}^{-}$ & 217 & 12 & 7 \\
$\mathrm{Cr}_{3} \mathrm{O}_{8}{ }^{-}$ & 284 & 2 & 5 \\
$\mathrm{Cr}_{3} \mathrm{O}_{9}^{-}$ & 300 & 100 & 89 \\
$\mathrm{HCr}_{3} \mathrm{O}_{10}$ & 317 & 10 & - \\
$\mathrm{Cr}_{4} \mathrm{O}_{11}$ & 384 & 27 & 14 \\
$\mathrm{Cr}_{4} \mathrm{O}_{12}{ }^{-}$ & 400 & 97 & 62 \\
$\mathrm{HCr}_{4} \mathrm{O}_{13}^{-}$ & 417 & 2 & - \\
$\mathrm{Cr}_{5} \mathrm{O}_{14}^{-}$ & 484 & 26 & 11 \\
$\mathrm{Cr}_{5} \mathrm{O}_{15}{ }^{-}$ & 500 & 37 & 15 \\
$\mathrm{Cr}_{6} \mathrm{O}_{17}^{-}$ & 584 & 7 & 2 \\
\hline
\end{tabular}

laser hit the surface and produced ablation, whereas the $266 \mathrm{~nm}$ radiation was directed through the expanding laser plume at an elevation of $\sim 2.5 \mathrm{~mm}$ above the target. In these experiments the $337 \mathrm{~nm} \mathrm{CrO}_{3}$ laser ablation was performed at a $\sim 5 \times 10^{6} \mathrm{~W} / \mathrm{cm}^{2}$ irradiance, and the $266 \mathrm{~nm}$ excitation at an irradiance estimated to $\sim 5 \times 10^{9} \mathrm{~W} / \mathrm{cm}^{2}$. Without $266 \mathrm{~nm}$ excitation, negative cluster ions were produced in the 200 to 600 $\mathrm{m} / \mathrm{z}$ range (Table 3 ). However, smaller species were observed when the $266 \mathrm{~nm}$ excitation was applied, as shown by the subtraction of mass spectra obtained with and without post ablation excitation (Figure 9). The additional energy imparted to cluster anions by the 266 $\mathrm{nm}$ laser caused fragmentation, producing smaller entities. This is consistent with the idea that increased laser irradiance or pulse laser duration, which respectively increase photon density and laser-ion interaction time, cause simultaneous production, and fragmentation of cluster ions. Indeed, $266 \mathrm{~nm}$ laser excitation had the same influence on the ensemble of cluster ions produced as did increased irradiance or pulse duration:

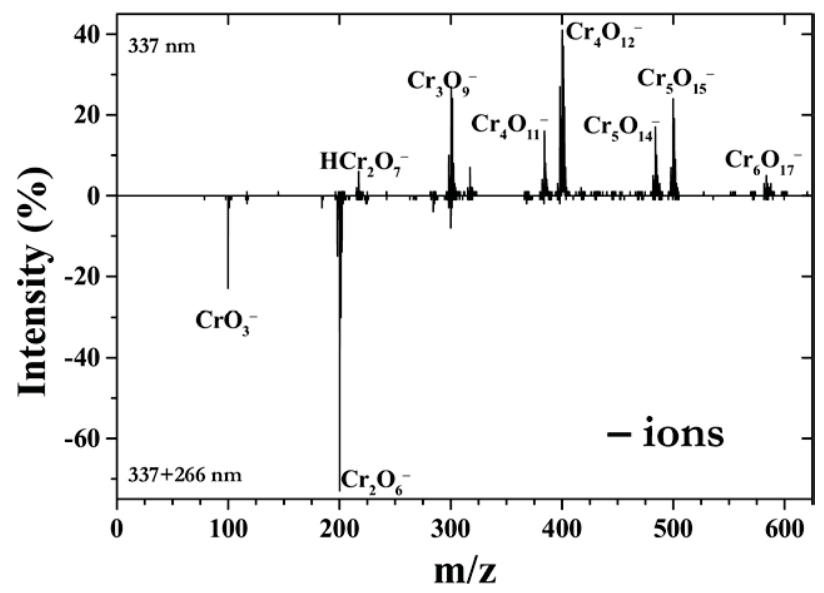

Figure 9. Subtraction of TOF-MS $\mathrm{CrO}_{3}$ mass spectra obtained with and without post ablation excitation in the gas phase at 266 $\mathrm{nm}$. Laser ablation of chromium trioxide is performed at $337 \mathrm{~nm}$.
Table 4. Bond strengths in diatomic MO molecules for first row transition metal compounds*

\begin{tabular}{lccc}
\hline $\mathrm{MO}$ & $\mathrm{D}^{\circ}{ }_{298}(\mathrm{eV})$ & $\mathrm{MO}$ & $\mathrm{D}^{\circ}{ }_{298}(\mathrm{eV})$ \\
\hline \hline $\mathrm{ScO}$ & $7.06 \pm 0.12$ & $\mathrm{FeO}$ & $4.05 \pm 0.18$ \\
$\mathrm{YO}$ & $7.16 \pm 0.12$ & $\mathrm{CoO}$ & $3.99 \pm 0.14$ \\
$\mathrm{TiO}$ & $6.97 \pm 0.10$ & $\mathrm{NiO}$ & $3.96 \pm 0.17$ \\
$\mathrm{VO}$ & $6.50 \pm 0.19$ & $\mathrm{CuO}$ & $2.79 \pm 0.22$ \\
$\mathrm{CrO}$ & $4.45 \pm 0.30$ & $\mathrm{ZnO}$ & $1.65 \pm 0.04$ \\
$\mathrm{MnO}$ & $4.18 \pm 0.43$ & & \\
\hline
\end{tabular}

*Data from [41].

the internal energy of ejected species was increased leading to fragmentation and observation of smaller ions.

Consequently, increased fragmentation is likely the main cause for the reduction of large cluster ion yield when laser irradiance is increased. The greater yield of the less oxygenated species for a given $\mathrm{M}_{x} \mathrm{O}_{1}^{-}$series at high laser irradiance may well be the result of fragmentation involving oxygen elimination. This assessment was supported by the PSD behavior of $\mathrm{Cr}_{4} \mathrm{O}_{10}{ }^{+}$ion (Figure 8). According to the dissociation energy of diatomic MO molecules (Table 4), the fragmentation of MO neutrals, especially for $3 d^{5+x}$ metals $(x>0)$ does not require large amounts of energy. Moreover, the photon density used in the high irradiance experiments lead to efficient dissociation of MO neutrals. For lower irradiance, photodissociation processes were limited, especially for $\mathrm{ScO}, \mathrm{TiO}$ and $\mathrm{VO}$ species which instead may be photoionized. This leads to the formation of a $\mathrm{MO}^{+}$ion since $\mathrm{MO}$ ionization and dissociation energies are similar (Tables 4,5$)$. As an example the $\mathrm{D}_{298}^{0}(\mathrm{TiO})$ is $0.15 \mathrm{eV}$ higher than the IE(TiO), [41, 42] consequently ionization is favored versus dissociation. For $3 d^{5+x}$ metals $(\mathrm{Cr}, \mathrm{Mn}, \mathrm{Fe}, \mathrm{Co}, \mathrm{Ni}, \mathrm{Cu}$ and $\mathrm{Zn}), \mathrm{MO}^{+}$ion intensity is very low. This may be due to an intense fragmentation of $\mathrm{MO}$ neutrals under laser irradiation at all laser irradiance values. These dissociation reactions could be linked to a significant yield of $\mathrm{O}^{-}$ions [28]. No thermodynamic data are available for larger $\mathrm{MO}_{2}$ and $\mathrm{MO}_{3}$ species, but it may be assumed that they could also be fragmented. According to this and results reported in Figure 6, the production of less oxygenated species by laser ablation could be well explained by dissociation in the gas phase, which induces the release of atomic or molecular oxygen and also by a noncongruent laser interaction (see the behavior of copper oxide reported in Figure 6). Both explanations appear to be valid, and their relative importance are thought to be

Table 5. Ionization energy IE of $\mathrm{M}$ and diatomic $\mathrm{MO}$ species for $\mathrm{M}=\mathrm{Ti}, \mathrm{V}$, and $\mathrm{Cr}^{*}$

\begin{tabular}{lcc}
\hline Transition metal & $\mathrm{IE}(\mathrm{M})$ in eV & $\mathrm{IE}(\mathrm{MO})$ in eV \\
\hline \hline Titanium & 6.828 & $6.819 \pm 0.006$ \\
Vanadium & $6.746 \pm 0.002$ & $7.239 \pm 0.001$ \\
Chromium & 6.767 & $7.85 \pm 0.02$ \\
\hline
\end{tabular}

*Data from [42]. 
highly dependant of the investigated transition-metal oxide.

\section{Study of Cluster Ion Formation by LA-MS}

Recently, Cuynen et al. [43] and Van Ham et al. [44] considered the energy randomization concept and the desorption-ionization (DI) model to be adequate to describe the formation of detected ions. In the DI model $[45,46]$, desorption (or ablation) and ionization occur successively after photon bombardment in different regions of the selvedge. Molecular and pseudomolecular species as ion pairs or neutrals are first emitted from the solid according to fast thermal or sputtering processes. After that desorbed or ablated entities are ionized according to various processes including adduct addition, electron capture, electron ionization, chargetransfer, and also photoionization. Depending on the distance from the photon impact at the sample surface atomic, pseudomolecular or molecular species were thought to be ejected in vacuum during the desorption (or ablation) step. It was also reported that low $\mathrm{m} / \mathrm{z}$ ions can be generated by unimolecular dissociation of the resulting species. This concept was supported by experimental [10, 21] and theoretical studies [47, 48]. In this context, the nascent model $[49,50]$ may be seen as an extension of DI model. In this model, ions directly emitted from the surface are thought to be efficiently neutralized before they can escape from the surface region due to rapid electronic transition rates $\left(10^{-14}\right.$ $10^{-16} \mathrm{~s}^{-1}$ ). Ions could consequently survive only if they are formed at some distance from the surface. Therefore they are thought to result from neutral dissociation. However, another model has been postulated to account for the emission of atomic ions [51, 52]. The surprising high-energy of some positive ions when various alkaline and alkaline earth salts or oxides were irradiated at low irradiance and several other experimental evidences suggested that atomic ions may be emitted from the surface according to an electrostatic emission mechanism. The emission is strongly enhanced by the increase of surface defects, especially oxygen vacancies. In this model it is proposed that positive atomic ion emission was due to cations adsorbed on the surface at sites located above occupied electron traps, i.e., oxygen vacancy defect, so-called adions. Ion emission occurs when laser removes electrons from the underlying electron trap and creates a hole. Emitted cations have ion velocities highly directed along the surface normal, which allow them to be quickly freed from the surface influence and to limit their neutralization. These expelled species could then act as cationization agent for neutral species expelled from the surface according to DI model.

These models provided an adequate basis to rationalize our results in terms of direct surface emission models such as the precursor model $[53,54]$.

The use of high laser irradiance increases the internal energy of resulting species and consequently their dis- sociation. Moreover, the Poisson distribution obtained in LA-MS as well as the study of binary oxide mixtures revealed the presence of both dissociation and recombination events during laser ablation process. Both processes explained why the LA-MS ion distributions of the four investigated vanadium oxides are so similar, especially at high irradiance. Recombination, dissociation, and oxygen release lead the same stable species to be produced.

One point remains unclear: when does dissociation processes occur? Fragmentation of desorbed (or ablated) species before and after ionization could be considered. $\mathrm{CrO}_{3}$ PSD and $\mathrm{CrO}_{3} 266 \mathrm{~nm}$ photodissociation experiments demonstrate dissociation after ionization, however fragmentation before ionization cannot be ruled out. This fragmentation may also be responsible for ionization if bonds in neutral species are heterolically broken.

Redox chemistry processes are also significant and merit comment. The production of mixed $\mathrm{Fe}-\mathrm{Cr}-\mathrm{O}$ ions in the study of iron chromium oxide mixture in LA-MS experiments and the high density of the species in the dense regions of the selvedge were consistent with fast collision rates, which lead to rapid recombination and dissociation processes before ionization can be achieved. The high density of particles in the selvedge near the surface also allows several other processes to take place, most notably oxidation and reduction. We have demonstrated in the previous section that the yield of oxygen species from the dense region of the selvedge was significant under photon bombardment, and these species could react in the dense region of the selvedge to oxidize other ablated species. Such processes could be compared with those observed in a study of metal ablated into an oxygen argon buffered atmosphere and co-deposited on a low-temperature surface [55-61]. In these experiments, gas-phase oxidation of metallic species by oxygen was identified using infrared spectroscopy. A large number of electrons are emitted after laser ablation that influence cluster ion formation [62]. These electrons are produced when the quantum of the photon is greater than $E_{y}$ the energy bandgap by the photoelectronic effect. A second source of electrons is sub-bandgap radiation, (i.e., photon energy $\mathrm{h} \nu<\mathrm{E}_{\mathrm{g}}$ ) where single photoelectron emission cannot occur [51]. Such electron emission has been reported for $5 \mathrm{eV}$ photon irradiation of $\mathrm{MgO}\left(\mathrm{E}_{\mathrm{g}}=7.8\right.$ $\mathrm{eV}$ ) and $\mathrm{NaNO}_{3} \mathrm{E}_{\mathrm{g}}=10 \mathrm{eV}$ [51]. Alternatively, the thermoelectronic effect may also lead to a significant production of electrons ([21] and reference herein). This process is favored at high laser irradiance, i.e., when the target was heated at high temperature. Large electron density was observed after irradiation for metal and also metal oxide surfaces in these conditions, but significant amounts of electrons were also produced when laser irradiance decreases by photoelectronic processes $[51,58]$. These electrons interact with the emitted cluster species and may lead to neutralization processes or reduction of metal valence state. The latter processes 
Table 6. Positive cluster ions observed in the $355 \mathrm{~nm}$ laser ablation mass spectrometry study of transition metal oxides

\begin{tabular}{|c|c|c|c|c|c|c|}
\hline Metal & Valence shell & Oxide & Charge carrier(s) & $\begin{array}{l}\text { Building } \\
\text { block(s) }\end{array}$ & $\begin{array}{l}\text { Building block } \\
\text { valence(s) }\end{array}$ & $\begin{array}{l}\text { Maximum number } \\
\text { of building blocks }\end{array}$ \\
\hline Scandium & $4 s^{2} 3 d^{1}$ & $\mathrm{Sc}_{2} \mathrm{O}_{3}$ & $\mathrm{ScO}^{+}$ & $\mathrm{Sc}_{2} \mathrm{O}_{3}$ & 3 & 19 \\
\hline Yttrium & $5 s^{2} 4 d^{1}$ & $\mathrm{Y}_{2} \mathrm{O}_{3}$ & $\mathrm{YO}_{1-2}^{+}, \mathrm{Y}_{2} \mathrm{O}_{2}^{+}$ & $\mathrm{Y}_{2} \mathrm{O}_{3}$ & 3 & 18 \\
\hline \multirow[t]{3}{*}{ Titanium } & $4 s^{2} 3 d^{2}$ & $\mathrm{TiO}$ & $\mathrm{TiO}_{0-1}{ }^{+}, \mathrm{TiO}_{2} \mathrm{H}_{1-2}{ }^{+}$ & $\mathrm{TiO}_{2}$ & 4 & 4 \\
\hline & & $\mathrm{Ti}_{2} \mathrm{O}_{3}$ & & & & 4 \\
\hline & & $\mathrm{TiO}_{2}$ & & & & 4 \\
\hline \multirow[t]{4}{*}{ Vanadium } & $4 s^{2} 3 d^{3}$ & VO & $\mathrm{VO}_{0-2}{ }^{+}$ & $\mathrm{V}_{2} \mathrm{O}_{3}$ & 3 & 5 \\
\hline & & $\mathrm{V}_{2} \mathrm{O}_{3}$ & & $\mathrm{VO}_{2}$ & 4 & 5 \\
\hline & & $\mathrm{V}_{2} \mathrm{O}_{4}$ & & $\mathrm{~V}_{2} \mathrm{O}_{5}$ & 5 & 5 \\
\hline & & $\mathrm{V}_{2} \mathrm{O}_{5}$ & & & & 2 \\
\hline \multirow[t]{2}{*}{ Chromium } & $4 s^{1} 3 d^{5}$ & $\mathrm{Cr}_{2} \mathrm{O}_{3}$ & $\mathrm{CrO}_{0-1}^{+}$ & $\mathrm{CrO}_{1-3}$ & $2,4,6$ & 2 \\
\hline & & $\mathrm{CrO}_{3}$ & $\mathrm{CrO}_{0-2}^{+}$ & $\mathrm{CrO}_{2-3}$ & 4,6 & 5 \\
\hline Molybdenum & $5 s^{1} 4 d^{5}$ & $\mathrm{MoO}_{3}$ & $\mathrm{MoO}_{0-2}^{+}$ & $\mathrm{MoO}_{2-3}$ & 4,6 & 4 \\
\hline Tungsten & $6 s^{2} 5 d^{4}$ & $\mathrm{WO}_{3}$ & $\mathrm{WO}_{1-3}^{+}$ & $\mathrm{WO}_{2-3}$ & 4,6 & 4 \\
\hline \multirow[t]{3}{*}{ Manganese } & $4 s^{2} 3 d^{5}$ & $\mathrm{MnO}$ & $\mathrm{MnO}_{\mathrm{O}-2}{ }^{+}, \mathrm{H}^{+}$ & $\mathrm{MnO}$ & 2 & 2 \\
\hline & & $\mathrm{Mn}_{2} \mathrm{O}_{3}$ & & & & 5 \\
\hline & & $\mathrm{MnO}_{2}$ & & & & 2 \\
\hline \multirow[t]{3}{*}{ Iron } & $4 s^{2} 3 d^{6}$ & $\mathrm{FeO}$ & $\mathrm{FeO}_{\mathrm{O}-1}{ }^{+}, \mathrm{H}^{+}$ & $\mathrm{FeO}$ & 2 & 5 \\
\hline & & $\mathrm{Fe}_{3} \mathrm{O}_{4}$ & $\mathrm{FeO}_{0-1}^{+}$ & & & 3 \\
\hline & & $\mathrm{Fe}_{2} \mathrm{O}_{3}$ & & & & 4 \\
\hline Nickel & $4 s^{2} 3 d^{7}$ & $\mathrm{NiO}$ & $\mathrm{Ni}^{+}$ & $\mathrm{NiO}$ & 2 & 1 \\
\hline \multirow[t]{2}{*}{ Cobalt } & $4 s^{2} 3 d^{8}$ & $\mathrm{CoO}$ & $\mathrm{CoO}_{0-1}^{+}$ & $\mathrm{CoO}$ & 2 & 2 \\
\hline & & $\mathrm{Co}_{3} \mathrm{O}_{4}$ & & & & 3 \\
\hline \multirow[t]{2}{*}{ Copper } & $4 s^{1} 3 d^{10}$ & $\mathrm{Cu}_{2} \mathrm{O}$ & $\mathrm{Cu}^{+}, \mathrm{Cu}_{2} \mathrm{O}^{+}, \mathrm{Cu}_{3}^{+}$ & $\mathrm{Cu}_{2} \mathrm{O}$ & 1 & 2 \\
\hline & & $\mathrm{CuO}$ & & $\mathrm{CuO}$ & 2 & 4 \\
\hline \multirow[t]{2}{*}{ Zinc } & $4 s^{2} 3 d^{10}$ & $\mathrm{ZnO}$ & $\mathrm{Zn}^{+}, \mathrm{ZnO}^{+}$ & $\mathrm{Zn}$ & 0 & 5 \\
\hline & & & & $\mathrm{ZnO}$ & 2 & \\
\hline
\end{tabular}

may be responsible for oxygen release, effectively stabilizing the resulting species. The occurrence of these mechanisms has been recently demonstrated for copper chlorides and small peptides deposited on different conductive and isolating surfaces [63-65]. Moreover, these electrons may also ionize neutrals species if their kinetic energy is high enough [21].

\section{Model of Cluster Ion Formation by LA-MS}

The observed cluster ions in LA-MS were thought to be mainly the result of the following processes: (1) direct emission of neutrals, electrons and atomic ions (and a smaller fraction of cluster ions) under photon bombardment according to desorption or ablation processes; (2) recombination, and oxidation, resulting from reactive low-energy collisions occurring in the denser area of the selvedge, (3) dissociation resulting from high-energy collisions or residual internal energy remaining in the ions, and (4) ionization of neutrals by cationization, anionization, electron capture/loss, photoionization, heterolytic bond dissociation, charge-transfer, or processes similar to electron impact. Several of these processes, i.e., ionization by cationization or anionization and photoionization in the gas phase, are also responsible for ionization of organic compounds in LD-MS or MALDI-MS experiments [60]. Finally, Jackson et al. [66] noted that atomic ions, such as $\mathrm{Sn}^{+}$and $\mathrm{O}^{-}$, may play some role in cluster formation of $(\mathrm{SnO})_{0-5} \mathrm{Sn}^{+},(\mathrm{SnO})_{1-6} \mathrm{O}^{-}$ and $(\mathrm{SnO})_{2-6}{ }^{+/-}$ion by laser ablation of $\mathrm{SnO}$ and $\mathrm{SnO}_{2}$ tin oxides. These authors suggested that these atomic ion may act as nucleation centers or may react with neutral $(\mathrm{SnO})_{x}$ to produce cluster ions. This is consistent with many of the processes that are proposed in this paper.

In the field of inorganic laser ablation mass spectrometry, heterolytic bond dissociation leading to ion formation could occur if the internal energy of species is high enough:

$$
\left(\mathrm{M}_{\mathrm{x}} \mathrm{O}_{\mathrm{y}}\right)_{\mathrm{n}}{ }^{*} \rightarrow\left(\mathrm{M}_{\mathrm{x}} \mathrm{O}_{\mathrm{y}}\right)_{\mathrm{a}} \mathrm{M}_{\mathrm{p}_{+}} \mathrm{O}_{\mathrm{q}_{+}}^{+}+\left(\mathrm{M}_{\mathrm{x}} \mathrm{O}_{\mathrm{y}}\right)_{\mathrm{b}} \mathrm{M}_{\mathrm{p}_{-}} \mathrm{O}_{\mathrm{q}_{-}}^{-}
$$

with $\mathrm{p}_{+}+\mathrm{p}_{-}=\mathrm{q}_{+}+\mathrm{q}_{-}=\mathrm{nx}-(\mathrm{a}+\mathrm{b}) \mathrm{x}$. This process is supported by the results of Foltin et al. who demonstrated the occurrence of these fragmentation-ionization processes when $\left(\mathrm{ZrO}_{2}\right)_{\mathrm{n}}$ neutral species absorbed two $193 \mathrm{~nm}$ photons at a $10^{7} \mathrm{~W} / \mathrm{cm}^{2}$ irradiance [67]. These authors also reported that an increase in laser irradiance led to an increase of fragmentation, which is in accordance with our results.

$\left(\mathrm{M}_{\mathrm{x}} \mathrm{O}_{\mathrm{y}}\right)_{\mathrm{n}}$ neutral clusters are produced by (1) direct emission from the surface under photon irradiation; (2) recombination or aggregation processes in the first steps after emission. The dense gaseous cloud that is formed in laser ablation experiments assists these latter processes by enabling a fast rate of efficient collisions and thermalization of resulting species. The excitation of neutrals may also take place in this region, occurring by thermal processes, collisions, or photon absorption.

The observed cluster ions could be regarded in this 
Table 7. Negative cluster ions observed in the $355 \mathrm{~nm}$ laser ablation mass spectrometry study of transition metal oxides

\begin{tabular}{|c|c|c|c|c|c|c|}
\hline Metal & Valence shell & Oxide & Charge carrier(s) & $\begin{array}{l}\text { Building } \\
\text { block(s) }\end{array}$ & $\begin{array}{l}\text { Building block } \\
\text { valence(s) }\end{array}$ & $\begin{array}{l}\text { Maximum number } \\
\text { of building blocks }\end{array}$ \\
\hline Scandium & $4 s^{2} 3 d^{1}$ & $\mathrm{Sc}_{2} \mathrm{O}_{3}$ & $\mathrm{ScO}_{1-2}{ }^{-}$ & - & - & - \\
\hline Yttrium & $5 s^{2} 4 d^{1}$ & $\mathrm{Y}_{2} \mathrm{O}_{3}$ & $\mathrm{YO}_{0-1}-$ & - & - & - \\
\hline \multirow[t]{3}{*}{ Titanium } & $4 s^{2} 3 d^{2}$ & $\mathrm{TiO}$ & $\mathrm{TiO}_{1-2}^{-}, \mathrm{OH}^{-}$ & $\mathrm{TiO}_{2}$ & 4 & 3 \\
\hline & & $\mathrm{Ti}_{2} \mathrm{O}_{3}$ & & & & 6 \\
\hline & & $\mathrm{TiO}_{2}$ & & & & 8 \\
\hline \multirow[t]{4}{*}{ Vanadium } & $4 s^{2} 3 d^{3}$ & VO & $\mathrm{VO}_{2-3}{ }^{-}$ & $\mathrm{V}_{2} \mathrm{O}_{3}$ & 3 & 8 \\
\hline & & $\mathrm{V}_{2} \mathrm{O}_{3}$ & & $\mathrm{VO}_{2}$ & 4 & 10 \\
\hline & & $\mathrm{V}_{2} \mathrm{O}_{4}$ & & $\mathrm{~V}_{2} \mathrm{O}_{5}$ & 5 & 6 \\
\hline & & $\mathrm{V}_{2} \mathrm{O}_{5}$ & & & & 8 \\
\hline \multirow[t]{2}{*}{ Chromium } & $4 s^{1} 3 d^{5}$ & $\mathrm{Cr}_{2} \mathrm{O}_{3}$ & $\mathrm{CrO}_{2-3}{ }^{-}$ & $\mathrm{CrO}_{2-3}$ & 4,6 & 3 \\
\hline & & $\mathrm{CrO}_{3}$ & $\mathrm{CrO}_{3}^{-}$ & $\mathrm{CrO}_{2-3}$ & 4,6 & 4 \\
\hline Molybdenum & $5 s^{1} 4 d^{5}$ & $\mathrm{MoO}_{3}$ & $\mathrm{MoO}_{3}^{-}$ & $\mathrm{MoO}_{2-3}$ & 4,6 & 5 \\
\hline Tungsten & $6 s^{2} 5 d^{4}$ & $\mathrm{WO}_{3}$ & $\mathrm{WO}_{3}{ }^{-}, \mathrm{OH}^{-}$ & $\mathrm{WO}_{2-3}$ & 4,6 & 3 \\
\hline \multirow[t]{3}{*}{ Manganese } & $4 s^{2} 3 d^{5}$ & $\mathrm{MnO}$ & $\mathrm{MnO}_{1-3}^{-}$ & $\mathrm{MnO}$ & 2 & 1 \\
\hline & & $\mathrm{Mn}_{2} \mathrm{O}_{3}$ & & & & 4 \\
\hline & & $\mathrm{MnO}_{2}$ & & & & 8 \\
\hline \multirow[t]{3}{*}{ Iron } & $4 s^{2} 3 d^{6}$ & $\mathrm{FeO}$ & $\mathrm{FeO}_{1-3}^{-}$ & $\mathrm{FeO}$ & 2 & 4 \\
\hline & & $\mathrm{Fe}_{3} \mathrm{O}_{4}$ & & & & 4 \\
\hline & & $\mathrm{Fe}_{2} \mathrm{O}_{3}$ & & & & 9 \\
\hline Nickel & $4 s^{2} 3 d^{7}$ & $\mathrm{NiO}$ & $\mathrm{NiO}_{1-2}^{-}, \mathrm{OH}^{-}$ & $\mathrm{NiO}$ & 2 & 5 \\
\hline \multirow[t]{2}{*}{ Cobalt } & $4 s^{2} 3 d^{8}$ & $\mathrm{CoO}$ & $\mathrm{CoO}_{1-3}^{-}, \mathrm{OH}^{-}$ & $\mathrm{CoO}$ & 2 & 2 \\
\hline & & $\mathrm{Co}_{3} \mathrm{O}_{4}$ & & & & 5 \\
\hline \multirow[t]{2}{*}{ Copper } & $4 s^{1} 3 d^{10}$ & $\mathrm{Cu}_{2} \mathrm{O}$ & $\mathrm{CuO}_{1-3}{ }^{-}, \mathrm{Cu}_{2} \mathrm{O}_{1-3}{ }^{-}$ & $\mathrm{Cu}_{2} \mathrm{O}$ & 1 & 2 \\
\hline & & $\mathrm{CuO}$ & & $\mathrm{CuO}$ & 2 & 6 \\
\hline Zinc & $4 s^{2} 3 d^{10}$ & $\mathrm{ZnO}$ & - & - & - & - \\
\hline
\end{tabular}

model as the condensation of $\mathrm{M}_{\mathrm{x}} \mathrm{O}_{\mathrm{y}}$ building blocks with $\mathrm{X}^{+/-}$charge carriers. The building blocks are hypothesized to be important participants not only in cluster formation but also in the reduction or oxidation events in the gas phase. The valence state of $M$ in the cluster ions corresponds to its most stable valence(s) in the gas phase and is not systematically related to its valence in the condensed phase target. $\mathrm{X}^{+/-}$charge carriers are from various impurities of the considered sample (alkaline or halogen ions) or ions from the studied compound (in that case the valence of $\mathrm{M}$ is not systematically the most stable). When ionization occurs by electron interaction, photoionization or charge-transfer, cluster ions only include building blocks. Moreover, ionization of small molecules or fast ejection of charged species from the surface can produce small ions capable of interaction with oxide neutrals, forming larger and more complex cluster ions. Building blocks and charge carriers for the first row transition-metal oxides are reported in Tables 6 and 7 .

Previously published results could be reanalyzed according to this model. As an example the positive ions produced by laser ablation of $\mathrm{Fe}_{2} \mathrm{O}_{3}{ }^{-} \mathrm{CaCrO}_{4}$ mixture [26] correspond to association of $\mathrm{CaO}, \mathrm{FeO}, \mathrm{CrO}_{2}$, and $\mathrm{CrO}_{3}$ building blocks with $\mathrm{Ca}^{+}, \mathrm{CrO}_{0-1}{ }^{+}$or $\mathrm{FeO}^{+}$ charge carriers. This analysis may also be applied to other oxides, mixture of oxides or alkaline and alkalineearth salts [11-21, 27, 46]. As an example, the building blocks and charge carriers observed in the study of $\mathrm{FeCrO}_{4}$ are reported in Figure 10, results have been discussed in another section above.

\section{Conclusions}

Cluster ions are thought to be formed by various processes, which mainly begin with the ejection of neutral species in vacuum under primary excitation, followed by various processes depending on the primary excitation source (laser pulsewidth, wavelength), the studied compounds, and the laser irradiance. Collisions and thermalization processes are thought to be

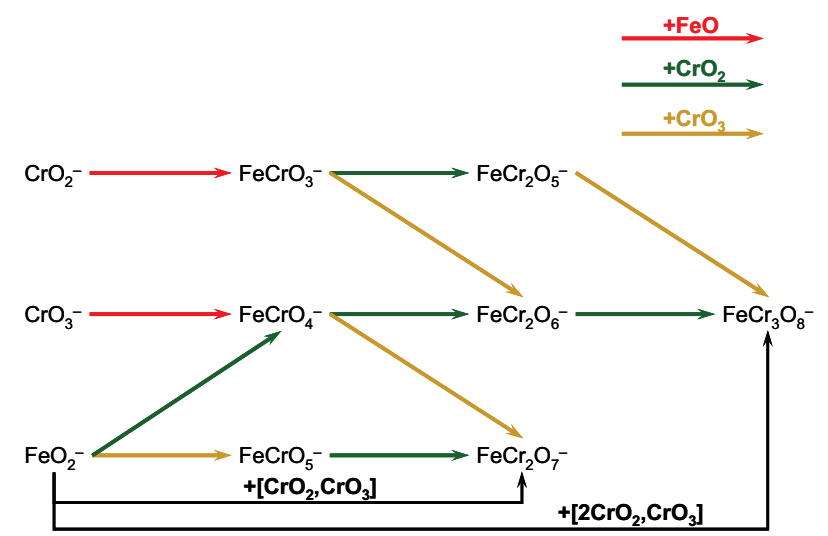

Figure 10. Example of building blocks and charge carriers observed in the study of iron chromite $\mathrm{FeCr}_{2} \mathrm{O}_{4}$ for negative ions at the $355 \mathrm{~nm}$ wavelength by LA-FTICRMS. For clarity, building blocks are given for monomeric $\mathrm{FeO}, \mathrm{CrO}_{2}$, and/or $\mathrm{CrO}_{3}$ species, the association of larger building blocks with $\mathrm{FeO}_{2}{ }^{-}, \mathrm{CrO}_{2}{ }^{-}$, and $\mathrm{CrO}_{3}{ }^{-}$have also to be considered as illustrated for $\mathrm{FeCr}_{2} \mathrm{O}_{7}{ }^{-}$and $\mathrm{FeCr}_{3} \mathrm{O}_{8}{ }^{-}$ions. 
of first importance to efficiently produce and stabilize large cluster ions.

Even though the studied compounds are quite different in terms of bound nature (principally ionic for the investigated compounds in this paper), some behaviors appear to be very similar to LA-MS [68-73] and MALDI-MS [74-77] experiments performed on organic compounds. Cationization/anionization processes as well as the formation of clusters, the interaction of emitted electrons with cluster ions, and the occurrence of reduction processes correspond to a general trend for laser ablation and laser desorption mass spectrometry [74-77].

\section{Acknowledgments}

The authors acknowledge N. Lourette for her help in TOF-MS experiments. FA gratefully acknowledges valuable discussions with Professor P. Bertrand, Professor G. Groenewold, Dr. A. Delcorte; he also acknowledges Dr. A. Gianotto and Professor G. Groenewold for editing.

\section{References}

1. Miller, J. C. Laser Ablation; Springer: Berlin and Heidelberg, 1994.

2. Miller, J. C.; Haglund, R. F. Laser Ablation and Laser Desorption; Academic Press: London, 1998.

3. Vertes, A.; Gijbels, R.; Adams, F. C. Laser Ionization Mass Spectrometry; Wiley: New York, 1993

4. Van Vaeck, L.; Struyf, H.; Van Roy, W.; Adams, F. Organic and Inorganic Analysis with Laser Microprobe Mass Spectrometry. Part I: Instrumentation and Methodology. Mass Spectrom. Rev. 1994, 13, 189208 .

5. Van Vaeck, L.; Struyf, H.; Van Roy, W.; Adams, F. Organic and Inorganic Analysis with Laser Microprobe Mass Spectrometry. Part II: Applications. Mass Spectrom. Rev. 1994, 13, 209-232.

6. Amoruso, S.; Bruzzese, R.; Spinelli, N.; Velotta, R. Characterization of Laser-Ablation Plasmas. J. Phys. B At. Mol. Opt. Phys. 1999, 32, R131R172.

7. Haglung, R. F. Microscopic and Mesoscopic Aspects of Laser-Induced Desorption and Ablation. Appl. Surf. Sci. 1996, 96/98, 1-13.

8. Knochenmuss, R.; Zhigilei, L. V. Molecular Dynamics Model of Ultraviolet Matrix-Assisted Laser Desorption/Ionization Including Ionization Processes. J. Phys. Chem. B 2005, 109, 22947-22957.

9. Cheng, C.; Wu, A. Q.; Xu, X. Molecular Dynamics Simulation of Ultrafast Laser Ablation of Fused Silica. J. Phys. Conf. Ser. 2007, 59, 100.

10. Liu, X.-H.; Zhang, X.-G.; Li, Y.; Wang, X.-Y.; Lou, N.-Q. Cluster Formation by Direct Laser Vaporization: Eevidence for the Twofold Mechanism. Chem. Phys. Lett. 1998, 288, 804-808.

11. Dennemont, J.; Landry, J. C.; Chevalley, J. Y.; Jaccard, J. The Laser Microprobe Mass Analyser as a Tool for the Characterization of Inorganic Substances.Analusis171391989145

12. Lafargue, P. E.; Gaumet, J. J.; Muller, J. F.; Labrosse, A. Laser Ablation of Silica: Study of Induced Clusters by Fourier Transform Ion Cyclotron Resonance Mass Spectrometry. J. Mass Spectrom. 1996, 31, 623-632.

13. Gibson, J. K. Laser Ablation Synthesis of Lanthanide Oxide Clusters: Mechanisms and Chemistry. J. Appl. Phys. 1995, 78, 1274-1280.

14. Hachimi, A.; Millon, E.; Poitevin, E.; Muller, J.-F. Etude de l'effet de l'hydratation et de la nature du sel sur la formation des clusters de chrome par ablation laser. Analusis 1993, 21, 11-19.

15. Hachimi, A.; Poitevin, E.; Krier, G.; Muller, J. F.; Ruiz-Lopez, M. F. Study of the Mechanism of Chromium Cluster Formation by Laser Microprobe Mass Spectrometry. Correlation with Theoretical Computations. Int. J. Mass Spectrom. Ion Processes 1995, 144, 23-45.

16. Liu, X.-H.; Zhang, X.-G.; Li, Y.; Wang, X.-Y.; Lou, N.-Q. Generation of Titanium Oxide Clusters of Relatively Large Size. Int. J. Mass Spectrom. 1998, 177, L1-L4.

17. Chaoui, N.; Hachimi, A.; Millon, E.; Muller, J. F. Characterization of Lead Oxides by Laser Microprobe Coupled with Mass Spectrometry in Resonantant and nonresonant mode: Application to Amorphous Silicates Containing Lead. Analusis 1996, 24, 146-151.

18. Musselman, I. H.; Linton, R. W.; Simons, D. S. Cluster Ion Formation Under Laser Bombardment. Studies of Recombination Using Isotope Labeling. Anal. Chem. 1988, 60, 110-114

19. Aubriet, F.; Maunit, B.; Muller, J.-F. Studies on Alkali and Alkaline Earth Chromate by Time-of-Flight Laser Microprobe Mass Spectrometry and Fourier Transform Ion Cyclotron Resonance Mass Spectrome- try. Part II: Understanding Cluster Ion Formation. Int. J. Mass Spectrom. 2000, 198, 213-234

20. Maunit, B.; Hachimi, A.; Calba, P. J.; Krier, G.; Muller, J. F. A New Method for the Determination of Iron Oxidation States by Resonant and Nonresonant Ionization Mass Spectrometry. Rapid Commun. Mass Spectrom. 1995, 9, 225-229.

21. Aubriet, F.; Muller, J.-F. About the Atypical Behavior of $\mathrm{CrO}_{3}, \mathrm{MoO}_{3}$ and $\mathrm{WO}_{3}$ during Their UV Laser Ablation/Ionization. J. Phys. Chem. A 2002, 106, 6053-6059.

22. Aubriet, F.; Poleunis, C.; Muller, J.-F.; Bertrand, P. Laser Ablation and Secondary Ion Mass Spectrometry of Inorganic Transition-Metal Compounds. Part I: Comparison Between Static TOF-SIMS and LA-FTICRMS. J. Mass Spectrom. 2006, 41, 527-542.

23. Spengler, B.; Kirsch, D.; Kaufmann, R. Fundamental Aspects of Postsource Decay in Matrix-Assisted Laser Desorption Mass Spectrometry. I: Residual Gas Effects. J. Phys. Chem. 1992, 96, 9678-9684.

24. Manoharan, S. S.; Kumar, N. R. S.; Patil, K. C. Preparation of Fine Particle Chromites: A Combustion Approach. Mater. Res. Bull. 1990, 25 731-738.

25. Aubriet, F.; Poleunis, C.; Bertrand, P. Characterization of Lead-Titanium-Oxygen Compounds by Static SIMS. Surf. Interface Anal. 2002, 34 $754-758$.

26. Aubriet, F.; Maunit, B.; Muller, J.-F. Speciation of Chromium Compounds by Laser Ablation/Ionization Mass Spectrometry and a Study of Matrix Effects. Int. J. Mass Spectrom. 2001, 209, 5-21.

27. Aubriet, F.; Maunit, B.; Courrier, B.; Muller, J. F. Studies of the Chromium Oxygenated Cluster Ions Produced During the Laser Ablation of Chromium Oxides by Laser Ablation/Ionization Fourier Transform Ion Cyclotron Resonance Mass Spectrometry. Rapid Commun. Mass Spectrom. 1997, 11, 1596-1601.

28. Flamini, C.; Ciccioli, A.; Traverso, P.; Gnecco, F.; Giardini Guidoni, A.; Mele, A. Laser-Induced Evaporation, Reactivity, and Deposition of $\mathrm{ZrO}_{2}, \mathrm{CeO}_{2}, \mathrm{~V}_{2} \mathrm{O}_{5}$, and mixed Ce-V oxides. Appl. Surf. Sci. 2000, 168, $104-107$.

29. Romeo, M.; Bak, K.; El Fallah, J.; Le Normand, F.; Hilaire, L. XPS. Study of the Reduction of Cerium Dioxide. Surf. Interface Anal. 1993, 20, 508-512.

30. Sol, C.; Tilley, R. J. D. Ultraviolet Laser Irradiation Induced Chemical Reactions of Some Metal Oxides. J. Mater Chem. 2001, 11, 815-820.

31. Nishikawa, Y.; Yoshida, Y.; Tanaka, K. Ion Energy Distribution of KrF Laser Ablation. Jpn. J. Appl. Phys. 1992, 31, L524-L526.

32. Qin, Q.-Z.; Han, Z.-H.; Dang, H.-J. An Angle-Resolved Time-of-Flight Mass Spectrometric Study of Pulsed Laser Ablated $\mathrm{Ta}_{2} \mathrm{O}_{5}$. J. Appl. Phys. 1998, 83, 6082-6088.

33. Park, S. M.; Moon, J. Y. Laser Ablation of a $\mathrm{Pb}\left(\mathrm{Zr}_{\mathrm{x}} \mathrm{Ti}_{1-\mathrm{x}}\right) \mathrm{O}_{3}$ Target in a Pulsed Oxygen Jet. Appl. Surf. Sci. 2001, 174, 87-92.

34. Pramann, A.; Rademann, K. Mass-Spectrometric Study of Formation and Stability of Manganese and Manganese Oxide Cluster Anions. Int. J. Mass Spectrom. 1999, 185/187, 673-683.

35. Fielicke, A.; Meijer, G.; von Helden, G. Infrared Spectroscopy of Niobium Oxide Cluster Cations in a Molecular Beam: Identifying the Cluster Structures. J. Am. Chem. Soc. 2003, 125, 3659-3667.

36. Jarrold, M. F.; Bower, J. E. Collision-Induced Dissociation of Silicon Clluster ions. J. Phys. Chem. 1988, 92, 5702-5705.

37. Gianotto, A. K.; Rawlinson, J. W.; Cossel, K. C.; Olson, J. E.; Appelhans, A. D.; Groenewold, G. S. Hydration of Alumina Cluster Anions in the Gas Phase. J. Am. Chem. Soc. 2004, 126, 8275-8283.

38. Drewnick, F.; Wieser, P. H. A Laser Ablation Electron Impact Ionization Time-of-Flight Mass Spectrometer for Analysis of Condensed Materials. Rev. Sci. Instrum. 2002, 73, 3003-3006.

39. Gibson, J. K. Lanthanide Oxide Cluster Ions Generated by Vacuum Laser Ablation: Metal Valence Effects on Cluster Compositions. J. Phys. Chem. 1994, 98, 11321-11330.

40. Zhang, X.; Wang, X.; Lou, N.-Q. Formation Dynamics of Atomic Clusters. Prog. Nat. Sci. 1997, 7, 129-137.

41. CRC Handbook of Chemistry and Physics, 76th ed.; CRC: Boca Raton Florida, 1995/1996

42. http:/webbook.nist.gov/

43. Cuynen, E.; Van Vaeck, L.; Van Espen, P. Speciation Analysis of Oxides with Static Secondary Ion Mass Spectrometry. Rapid. Commun. Mass Spectrom. 1999, 13, 2287-2301.

44. Van Ham, R.; Van Vaeck, L.; Adams, F. C.; Adriaens, A. Systematization of the Mass Spectra for Speciation of Inorganic Salts with Static Secondary Ion Mass Spectrometry. Anal. Chem. 2004, 76, 2609-2617.

45. Cooks, R. G.; Busch, K. L. Matrix Effects, Internal Energies and MS/MS Spectra of Molecular Ions Sputtered from Surfaces. Int. J. Mass Spectrom. Ion Phys. 1983, 53, 111-124.

46. Struyf, H.; Van Vaeck, L.; Van Grieken, R. Desorption/Ionization of Inorganic Compounds in Fourier Transform Laser Microprobe Mass Spectrometry with External Ion Source. Rapid Commun. Mass Spectrom. 1996, 10, 551-561.

47. Wojciechowski, I. A.; Bertrand, P.; Medvedeva, M. V.; Ferleger, V. K The Degree of Positive Ionization of Sputtered Metal Clusters. Nucl. Instrum. Method B 2001, 179, 32-36.

48. Delcorte, A.; Garrison, B. J. Desorption of Large Organic Molecules Induced by keV Projectiles. Nucl. Instrum. Method B 2001, 180, 37-43.

49. Gerhard, W.; Plog, C. Secondary Ion Emission by Nonadiabatic Dissociation of Nascent Ion Molecules with Energies Depending on Solid Composition. Zeitschrift Phys B Condensed Matter 1983, 54, 59-70. 
50. Plog, C.; Gerhard, W. Secondary Ion Emission by Nonadiabatic Dissociation of Nascent Ion Molecules with Energies Depending on Solid Composition. Zeitschrift Phy. B Condensed Matter. 1983, 54, 71-86.

51. Dickinson, J. T.; Ermer, D. R.; Shin, J.-J.; Langford, S. C. Mechanisms of Laser Desorption of Positive Ions and Plume Formation on Ionic Crystals. Appl. Surf. Sci. 1998, 127/129, 7-20.

52. Dickinson, J. T. Low Fluence Laser Desorption and Plume Formation from Wide Bandgap Crystalline Materials. In Laser Ablation and Desorption; Miller, J. C.; Haglung, R. F., Eds.; Academic Press: San Diego, 1998; pp 139-172.

53. Benninghoven, A. Some Aspects of Secondary Ion Mass Spectrometry of Organic Compounds. Int. J. Mass Spectrom. Ion Phys. 1983, 53, 85-99.

54. Plog, C.; Wiedmann, L.; Benninghoven, A. Empirical Formula for the Calculation of Secondary Ion Yields from Oxidized Metal Surfaces and Metal Oxides. Surf. Sci. 1977, 67, 565-580.

55. Andrews, L.; Chertihin, G. V.; Ricca, A.; Bauschlicher, C. W. Reactions of Laser-Ablated Iron Atoms with Oxygen Molecules: Matrix Infrared Spectra and Density Functional Calculations of $\mathrm{OFeO}, \mathrm{FeOO}$, and $\mathrm{Fe}\left(\mathrm{O}_{2}\right)$. J. Am. Chem. Soc. 1996, 118, 467-470.

56. Chertihin, G. V.; Andrews, L. Reactions of Laser Ablated Titanium, Zirconium, and Hafnium Atoms with Oxygen Molecules in Condensing Argon. J. Phys. Chem. 1995, 99, 6356-6366.

57. Chertihin, G. V.; Andrews, L. Reactions of Laser-Ablated Manganese Atoms with Dioxygen. Infrared Spectra of $\mathrm{MnO}, \mathrm{OMnO}, \mathrm{Mn}\left(\mathrm{O}_{2}\right)$ $(\mathrm{MnO})_{2}$, and Higher Oxide Complexes in Solid Argon. J. Phys. Chem. A 1997, 101, 8547-8553.

58. Chertihin, G. V.; Andrews, L.; Bauschlicher, C. W. Reactions of LaserAblated Copper Atoms with Dioxygen. Infrared Spectra of the Copper Oxides $\mathrm{CuO}, \mathrm{OCuO}, \mathrm{CuOCuO}$, and $\mathrm{OCuOCuO}$ and Superoxide $\mathrm{CuOO}$ in Solid Argon. J. Phys. Chem. A 1997, 101, 4026-4034.

59. Chertihin, G. V.; Bare, W. D.; Andrews, L. Reactions of Laser-Ablated Vanadium Atoms with Dioxygen. Infrared Spectra of $\mathrm{VO}, \mathrm{VO}_{2}, \mathrm{OOVO}_{2}$ and $\mathrm{V}_{2} \mathrm{O}_{2}$ in Solid Argon. J. Phys. Chem. A 1997, 101, 5090-5096.

60. Chertihin, G. V.; Citra, A.; Andrews, L.; Bauschlicher, C. W. Reactions of Laser-Ablated Cobalt Atoms with $\mathrm{O}_{2}$. Infrared Spectra of Cobalt Oxides in Solid Argon. J. Phys. Chem. A 1997, 101, 8793-8802.

61. Citra, A.; Chertihin, G. V.; Andrews, L.; Neurock, M. Reactions of Laser-Ablated Nickel Atoms with Dioxygen. Infrared Spectra and Density Functional Calculations of Nickel Oxides $\mathrm{NiO}, \mathrm{ONiO}, \mathrm{Ni}_{2} \mathrm{O}_{2}$, and $\mathrm{Ni}_{2} \mathrm{O}_{3}$, Superoxide $\mathrm{NiOO}$, Peroxide $\mathrm{Ni}\left(\mathrm{O}_{2}\right)$, and Higher Complexes in Solid Argon. J. Phys. Chem. A 1997, 101, 3109-3118.

62. Bogaerts, A.; Chen, Z.; Gijbels, R.; Vertes, A. Laser Ablation for Analytical Sampling: What Can We Learn from Modeling? Spectrochim. Acta B 2003, 58, 1867-1893.

63. Knochenmuss, R.; Zenobi, R. MALDI. Ionization: The Role of In-Plume Processes. Chem. Rev. 2003, 103, 441-452.
64. Zhang, J.; Frankevich, V.; Knochenmuss, R.; Friess, S. D.; Zenobi, R. Reduction of $\mathrm{Cu}(\mathrm{II})$ in Matrix-Assisted Laser Desorption/Ionization Mass Spectrometry. J. Am. Soc. Mass Spectrom. 2003, 14, 42-50.

65. Frankevich, V. E.; Zhang, J.; Friess, S. D.; Dashtiev, M.; Zenobi, R. Role of Electrons in Laser Desorption/Ionization Mass Spectrometry. Anal. Chem. 2003, 75, 6063-6067.

66. Jackson, P.; Fisher, K. I. Dance, I. G.; Gadd, G. E.; Willett, G. D. The Structure of Gas Phase Tin Oxide Ions Generated by Laser Ablation: A Combined Fourier Transform Mass Spectrometry and Density Functional Theory Study. J. Cluster Sci. 2002, 13, 165-187.

67. Foltin, M.; Stueber, G. J.; Bernstein, E. R. Investigation of the Structure, Stability, and Ionization Dynamics of Zirconium Oxide Clusters. J. Chem. Phys. 2001, 114, 8971-8989.

68. Neubert, H.; Hider, R. C.; Cowan, D. A. Speciation of Fe(III)-Chelate Complexes by Electrospray Ionization Ion Trap and Laser Desorption/ Ionization Fourier Iransform Ion Cyclotron Resonance Mass Spectrometry. Rapid Commun. Mass Spectrom. 2002, 16, 1556-1561.

69. Cassat, P.; Muller, J. F.; Manuelli, P.; Vichot, A.; Colombet, P. In Situ Detection of Triethanolamine in Portland Cement by Laser Desorption and Matrix-Assisted Laser Desorption/Ionization Fourier Transform Ion Cyclotron Resonance Mass Spectrometry. Rapid Commun. Mass Spectrom. 1997, 11, 1612-1615.

70. Ruch, D.; Boes, C.; Zimmer, R.; Migeon, H.-N.; Muller, J. F. Surface Oxidation of Styrene Butadiene Copolymers: Study by Laser Ablation and Secondary Ion Mass Spectrometry. J. Appl. Polym. Sci. 2003, 87, 1910-1917.

71. Ruch, D.; Boes, C.: Zimmer, R.; Muller, J. F.; Migeon, H.-N. Quantitative Analysis of Styrene Butadiene Copolymers Using S-SIMS and LAFTICRMS. Appl. Surf. Sci. 2003, 203/204, 566-570.

72. Ruch, D.; Muller, J. F.; Migeon, H. N.; Boes, C.; Zimmer, R. Secondary Ion and Laser Ablation Mass Spectrometry for the Quantitative Characterization of Styrene-Butadiene Copolymers. J. Mass Spectrom. 2003, $38,50-57$.

73. Carré, V.; Vernex-Loset, L.; Krier, G.; Manuelli, P.; Muller, J.-F. Laser Desorption/Ionization Mass Spectrometry of Diesel Particulate Matter with Charge-Transfer Complexes. Anal. Chem. 2004, 76, 3979-3987.

74. Wong, C. K. L.; Dominic Chan, T.-W. Cationization Processes in Matrix-Assisted Laser Desorption/Ionization Mass Spectrometry: Attachment of Divalent and Trivalent Metal Ions. Rapid Commun. Mass Spectrom. 1997, 11, 513-519.

75. Dreisewerd, K. The Desorption Process in MALDI. Chem. Rev. 2003, 103, 395-426.

76. Karas, M.; Kruger, R. Ion Formation in MALDI: The Cluster Ionization Mechanism. Chem. Rev. 2003, 103, 427-440.

77. Delcorte, A.; Bour, J.; Aubriet, F.; Muller, J.-F.; Bertrand, P. Sample Metallization for Performance Improvement in Desorption/Ionization of Kilodalton Molecules: Quantitative Evaluation, Imaging Secondary Ion MS, and Laser Ablation. Anal. Chem. 2003, 75, 6875-6885. 